\title{
Effects of Siberian fir terpenes extract Abisil on antioxidant activity, autophagy, transcriptome and proteome of human fibroblasts
}

\author{
Anastasiya Lipatova ${ }^{1}$, George Krasnov ${ }^{1,2}$, Pavel Vorobyov ${ }^{1}$, Pavel Melnikov ${ }^{3}$, Olga Alekseeva ${ }^{1}$, \\ Yulia Vershinina ${ }^{1}$, Alexander Brzhozovskiy ${ }^{4}$, Daria Goliusova ${ }^{5}$, Faniya Maganova ${ }^{6}$, Natalia \\ Zakirova $^{1,2}$, Anna Kudryavtseva ${ }^{1,2}$, Alexey Moskalev ${ }^{1,7,8}$ \\ ${ }^{1}$ Engelhardt Institute of Molecular Biology, Russian Academy of Sciences, Moscow 119991, Russia \\ ${ }^{2}$ Center for Precision Genome Editing and Genetic Technologies for Biomedicine, Engelhardt Institute of Molecular \\ Biology, Russian Academy of Sciences, Moscow 119991, Russia \\ ${ }^{3}$ V. Serbsky National Research Center for Psychiatry and Narcology, Moscow 119034, Russia \\ ${ }^{4}$ Skolkovo Institute of Science and Technology, Moscow 121205, Russia \\ ${ }^{5}$ Vavilov Institute of General Genetics, Russian Academy of Sciences, Moscow 119991, Russia \\ ${ }^{6}$ Initium-Pharm, LTD, Moscow 142000, Russia \\ "Institute of Biology of Federal Research Center "Komi Science Center" of Ural Branch of RAS, Syktyvkar 167982, \\ Russia \\ ${ }^{8}$ Russian Clinical and Research Center of Gerontology, Moscow 129226, Russia
}

Correspondence to: Alexey Moskalev; email: amoskalev@list.ru

Keywords: terpenes, autophagy, proteome, fibroblasts, transcriptome

Received: July 27, $2020 \quad$ Accepted: July 23, 2021

Published: August 24, 2021

Copyright: (c) 2021 Lipatova et al. This is an open access article distributed under the terms of the Creative Commons Attribution License (CC BY 3.0), which permits unrestricted use, distribution, and reproduction in any medium, provided the original author and source are credited.

\section{ABSTRACT}

Background: Abisil is an extract of Siberian fir terpenes with antimicrobial and wound healing activities. Previous studies revealed that Abisil has geroprotective, anti-tumorigenic, and anti-angiogenic effects. Abisil decreased the expression of cyclin D1, E1, A2, and increased the phosphorylation rate of AMPK.

Objective: In the present study, we analyzed the effect of Abisil on autophagy, the mitochondrial potential of embryonic human lung fibroblasts. We evaluated its antioxidant activity and analyzed the transcriptomic and proteomic effects of Abisil treatment.

Results: Abisil treatment resulted in activation of autophagy, reversal of rotenone-induced elevation of reactive oxygen species (ROS) levels and several-fold decrease of mitochondrial potential. Lower doses of Abisil (25 $\mu \mathrm{g} / \mathrm{ml}$ ) showed a better oxidative effect than high doses (50 or $125 \mu \mathrm{g} / \mathrm{ml}$ ). Estimation of metabolic changes after treatment with $50 \mu \mathrm{g} / \mathrm{ml}$ has not shown any changes in oxygen consumption rate, but extracellular acidification rate decreased significantly. Abisil treatment ( 5 and $50 \mu \mathrm{g} / \mathrm{ml}$ ) of MRC5-SV40 cells induced a strong transcriptomic shift spanning several thousand genes (predominantly, expression decrease). Among downregulated genes, we noticed an over-representation of genes involved in cell cycle progression, oxidative phosphorylation, and fatty acid biosynthesis. Additionally, we observed predominant downregulation of genes encoding for kinases. Proteome profiling also revealed that the content of hundreds of proteins is altered after Abisil treatment (mainly, decreased). These proteins were involved in cell cycle regulation, intracellular transport, RNA processing, translation, mitochondrial organization.

Conclusions: Abisil demonstrated antioxidant and autophagy stimulating activity. Treatment with Abisil results in the predominant downregulation of genes involved in the cell cycle and oxidative phosphorylation. 


\section{INTRODUCTION}

Life expectancy in economically developed countries gradually increases along with the burden of chronical diseases [1]. However, centenarians have several times higher delay of aging-related diseases [2]. It is well documented that some mammals live not only unusually longer but are also resistant to stress, tumor diseases and type 2 diabetes mellitus [3]. Based on these discoveries, geroscience conception suggests that by focusing not on specific diseases of aging, but on targeting the mechanisms of aging itself, it is possible to achieve more significant effects of prolonging a healthy period of life [4]. It may be promising to identify the effects of pharmacological compounds on gene activity patterns associated with molecular pathways of aging and longevity.

Substances that can slow down aging, the so-called geroprotectors, delay the onset of age-related diseases and reduce the mortality risks. It should be noted that potential geroprotectors could be not only synthetic drugs. Of greatest interest are sources of potential geroprotectors of natural origin, primarily from already known medicinal and food plants. They are the most tolerable and faster to put on a market.

At present, the geroprotective properties are revealed by the increase in the lifespan of model organisms. From this point of view such properties of many plant extracts were studied [5]. Another criteria for anti-aging drug is the effect on the basic molecular and cellular processes of aging [6]. A variety of studies has demonstrated that disruption of cellular homeostasis and molecular stability through increased formation of free radicals, lipid peroxidation, and protein glycoxidation is important for cellular senescence and organismal aging [7] confirming the theory of oxidative stress, proposed by Denham Harman [8], to be one of the mechanisms of aging. Nevertheless, the antioxidant properties of the molecules in vitro are unlikely to explain most beneficial pharmacological effects in vivo [9]. It is more probable that such compounds as xenobiotics trigger a mild oxidative stress and then the expression of genes of internal antioxidant defense, mitohormesis [10] or other stress resistance pathways, such as autophagy [11] or positive epigenetic shift [12]. A decrease in the activity of the electron transport chain and removal of defective mitochondria are the key modulators of oxidative stress reaction [13]. Inducible mitophagy can play a decisive role in reducing the formation of free radicals $[14,15]$.

Our previous studies have shown that Abisil, an extract of Siberian fir terpenes, in some aspects preserve gene expression profile of older cells characteristics in vitro close to characteristics of younger cells. Abisil also induced expression of a range of anti- and pro- tumorigenic genes [16]. Other in vitro and in vivo studies have demonstrated anti-tumorigenic and antiangiogenic effect of Abisil [17]. In the present study, we investigated the effect of Abisil on cell survival and metabolic rate, the processes of auto- and mitophagy, as well as genome-wide gene expression.

\section{MATERIALS AND METHODS}

\section{Reagents and cell treatment}

Abisil in the form of resin was kindly provided by Initium-Pharm LLC (Moscow, Russia; https://initiumpharm.com/). Abisil was dissolved in DMSO to obtain a stock for treatment of cell cultures.

All cells were maintained in Dulbecco's modified Eagle's medium (DMEM) (PanEco, Moscow, Russia) supplemented with $10 \%$ fetal bovine serum (FBS, Biosera) and $50 \mathrm{U} / \mathrm{ml}$ penicillin and $50 \mu \mathrm{g} / \mathrm{ml}$ streptomycin (PanEco) in a humidified atmosphere containing $5 \% \quad \mathrm{CO}_{2}$. Immediately prior to treatment, Abisil stock was diluted in serum-free DMEM; treatment was performed in DMEM containing 5\% FBS when cells were 50-70\% confluent. Negative controls were treated with an equal amount of DMSO diluted in DMEM supplemented with 5\% FBS.

\section{Oxidative stress assays}

MRC5-SV40 cells were seeded at a density of $4 \times 10^{4}$ cells/well in 12-well plates. Next day, Abisil treatment was performed in a wide range of concentrations (6-200 $\mu \mathrm{g} / \mathrm{ml})$. After 16 hours, cell oxidative stress was induced by treatment with $1 \mu \mathrm{M}$ of rotenone (SigmaAldrich, USA) for 1.5 hours. After that, the cells were stained with $10 \mu \mathrm{M}$ DHE (dihydroethidium, SigmaAldrich) for $35 \mathrm{~min}$ at $37^{\circ} \mathrm{C}$. The cells were trypsinized and resuspended in PBS (PanEco) supplemented with $2 \%$ FBS. Before measurement cells were stained with $1 \mu \mathrm{g} / \mathrm{ml}$ of DAPI (Sigma-Aldrich) as a viability assay. Fluorescence was detected using a BD LSR Fortessa cytofluorimeter (Beckman Dickinson). The analysis was performed using Flowing Software 2.0 (Perttu Terho, Turku Center for Biotechnology). The results were based on three independent experiments, each with three biological replicates.

\section{Mitochondrial potential assessment}

MRC5-SV40 and LECH-4 cells were seeded at a density of $4 \times 10^{4}$ cells/well in 12 -well plates. Next day, Abisil treatment was performed with a wide range of concentrations $(10-80 \mu \mathrm{g} / \mathrm{ml})$. After 16 hours, the cells were stained with $100 \mathrm{nM}$ and $200 \mathrm{nM}$ of TMRM (Thermo Fisher Scientific, USA), respectively, for 30 min at $37^{\circ}$ C. $10 \mu \mathrm{M}$ of CCCP (Sigma-Aldrich) was 
used as positive control. Before measurement cells were stained for viability with $1 \mu \mathrm{g} / \mathrm{ml}$ of DAPI (SigmaAldrich). Fluorescence was detected using a BD LSR Fortessa cytofluorimeter (Beckman Dickinson). The analysis was performed using Flowing Software 2.0 (Perttu Terho, Turku Center for Biotechnology). The results were based on three independent experiments with three biological replicates.

\section{Autophagy and mitophagy assays}

Autophagy was assessed on a panel of cell lines stably expressing mCherry-GFP-LC3 reporter frame. Treatment with Abisil was carried out in concentration $50 \mu \mathrm{g} / \mathrm{ml}$ for 16 hours. Rapamycin (R0395, Sigma-Aldrich) was used as a positive control.

To detect mitophagy in MRC5-SV40 and LECH-4 cells, concentrations of $50 \mu \mathrm{g} / \mathrm{ml}$ of Abisil were used for treatment for 24 hours. After incubation, the cells were stained with $200 \mathrm{nM}$ of MitoTracker Red CMXRos (Thermo Fisher Scientific) and $100 \mathrm{nM}$ of LysoTracker Green (Thermo Fisher Scientific) for 20 minutes at $37^{\circ} \mathrm{C}$.

Confocal microscopy was performed on the Nikon A1+MP confocal imaging system using an Apo TIRF 60x/1.49 oil DIC objective (numerical aperture=1.49; Nikon Japan), Apo LWD 40x/1.15 S water immersion objective (numerical aperture $=1.15$; Nikon Japan). Images were scanned sequentially using 488- and 561$\mathrm{nm}$ diode lasers in combination with a DM405/488/561/ 633-nm dichroic beam splitter. Differential Interference Contrast Imaging (DIC) microscopy was used to visualize cell contours. The images were analyzed with NIS-elements AR (Nikon Japan).

\section{Quantitative real-time PCR}

To analyze the level of mitochondrial DNA, total cellular DNA was extracted from the cells using GeneJET Genomic DNA Purification Kit (Thermo Fisher Scientific) and subsequently quantified by qPCR. qPCRmix-HS SYBR kit (Evrogen) was used according to the manufacturer's instructions, and the real-time PCR was performed on the Rotor-Gene Q Real-Time PCR system (Quigen). The real-time qPCR results were analyzed with $2^{-\Delta \Delta \mathrm{Ct}}$ method traditionally used for gene expression studies. We used genomic sequence of B2M gene as an endogenous control. All primer pairs used for qPCR are presented in the Table 1 .

\section{Measurement of mitochondrial function using the Seahorse XF-24 extracellular flux analyzer}

MRC5-SV40 cells were cultured in DMEM medium (Gibco, Thermo Fisher Scientific) containing $4.5 \mathrm{~g} / \mathrm{L}$ glucose, supplemented with $10 \%$ bovine serum (BioSera) and $2 \mathrm{mM}$ glutamine (PanEco). 40 hours before the experiment, the cells were seeded on 24-well Seahorse XFe24 Cell Culture Microplate (Agilent Technologies,) at a density of 12000 cells per well in $500 \mu$ l of growth medium without affecting comparison wells A1, B3, C4 and D6 and incubated at $+37^{\circ} \mathrm{C}$ in a $\mathrm{CO}_{2}$ incubator with a relative humidity of $95 \%$ and a $\mathrm{CO}_{2}$ content of $5 \%$. When the cells reached $45 \%$ of the monolayer (24 hours after seeding) they were treated with Abisil at a concentration of $50 \mu \mathrm{g} / \mathrm{ml}$ and incubated for 16 hours at $+37^{\circ} \mathrm{C}$ in a $\mathrm{CO}_{2}$ incubator with a relative humidity of $95 \%$ and a $\mathrm{CO}_{2}$ content of $5 \%$. On the day of the MitoStress Test experiment, the growth medium was removed, the cells were washed with warm DMEM medium without sodium bicarbonate and supplemented with $25 \mathrm{mM}$ glucose, $2 \mathrm{mM}$ sodium pyruvate (PanEko) and $2 \mathrm{mM}$ glutamine (PanEko) (2 times $300 \mu \mathrm{l}$ ), after which the experiment medium (described above, $500 \mu \mathrm{l}$ per well) was added and incubated for 45 minutes at $+37^{\circ}$ $\mathrm{C}$ in a non- $\mathrm{CO}_{2}$ incubator. The experiment medium was also added to the comparison wells. The following preparations were added to the ports of the Agilent Seahorse XF24 Sensor Cartridge prepared in accordance with the manufacturer's recommendations: Port A - 11 $\mu \mathrm{M}$ oligomycin $(1 \mu \mathrm{M}$ final concentration in well), Port $\mathrm{B}-24 \mu \mathrm{M}$ FCCP $(2 \mu \mathrm{M}$ final concentration in well $)$ and Port $\mathrm{C}-13 \mu \mathrm{M}$ Rot/AA ( $1 \mu \mathrm{M}$ final concentration in well). Then, the Oxygen Consumption Rates (OCR) were measured ( 3 measurements per injection) at $+37^{\circ} \mathrm{C}$ on the Seahorse Bioanalyzer instrument. After the measurement, the experiment medium was removed, 25 $\mu \mathrm{l}$ of RIPA buffer was added and the protein concentration was measured using a Bradford Reagent (Sigma B6916). OCR measurements were normalized to the total protein level.

On the day of the GlycoTest experiment, the growth medium was removed, the cells were washed with warm DMEM w/o sodium bicarbonate and supplemented with $2 \mathrm{mM}$ sodium pyruvate (PanEco) and $2 \mathrm{mM}$ glutamine (PanEco; 2 times $300 \mu \mathrm{L}$ ), added experiment medium $\left(500 \mu \mathrm{l}\right.$ per well) and incubated for 30 minutes at $+37^{\circ} \mathrm{C}$ in a non- $\mathrm{CO}_{2}$ incubator. The experiment medium was also added to the comparison wells. The following preparations were added to the ports of the Agilent Seahorse XF24 Sensor Cartridge prepared in accordance with the manufacturer's recommendations: Port A - 275 $\mathrm{mM}$ Glucose (25 mM final concentration in well), Port B - $12 \mu \mathrm{M}$ oligomycin $(1 \mu \mathrm{M}$ final concentration in well) and Port C - $650 \mathrm{mM}$ 2-deoxy-D-glucose (50 mM final concentration).

Then, the Extracellular Acidification Rate (ECAR) was measured (3 measurements per injection) at $+37^{\circ} \mathrm{C}$ on the Seahorse Bioanalyzer instrument. After the 
Table 1. Primers used for quantitative real-time PCR to evaluate mitochondrial genome cope number change after Abisil treatment.

\begin{tabular}{cccc}
\hline & Gene name & Primer name & Primer sequence (5'-3') \\
\hline 1 & $B 2 M$ & B2M-for & TGCTGTCTCCATGTTTGATGTATC T \\
2 & B2M-rev & TCTCTGCTCCCCACCTCTAAGT \\
3 & mitochondrial DNA, & Mito-G-for & CGCCTCACACTCATTCTCAA \\
4 & intergenic spacer & Mito-G-rev & CAAGGAAGGGGTAGGCTATG \\
5 & mitochondrial DNA, & ND1-for & CCCTACTTCTAACCTCCCTGTTCTTAT \\
6 & $M T-N D 1$ gene & ND1-rev & CATAGGAGGTGTATGAGTTGGTCGTA \\
\hline
\end{tabular}

measurement, the experiment medium was removed, $25 \mu \mathrm{l}$ of RIPA buffer was added, and the protein concentration was measured with a Bradford Reagent (Sigma B6916). ECAR measurements were also normalized to the total protein level.

\section{Evaluating cytotoxic effect of Abisil with MTS assay}

MRC5-SV40 cells were seeded at a density of $5 \times 10^{3}$ cells/well in a 96-well plate and cultured in $100 \mu \mathrm{l}$ of DMEM supplemented with 5\% FBS at $37^{\circ}$ C. 24 hours after seeding cells were treated with Abisil $(0 ; 9 ; 11 ; 15$; $25 ; 50 ; 93 ; 125,147$ and $186 \mu \mathrm{g} / \mathrm{ml}$ ) within 24 hours at $37^{\circ} \mathrm{C}$. The level of cell metabolic activity was evaluated using the MTS assay (CellTiter 96 AQueous NonRadioactive Cell Proliferation Assay (MTS), Promega) in accordance with the manufacturer's protocol. The optical density of the stained substance at $590 \mathrm{~nm}$, proportional to the metabolic rate of viable cells, was measured using a plate reader (Tecan). Then, the IC50 values were calculated by the regression analysis, as well as the concentrations at which the most intense cellular metabolism was observed.

\section{Western blotting}

MRC5-SV40 cells were cultured on $35 \mathrm{~mm}$ Petri dishes with confluency of $50 \%$, treatment with Abisil was carried out in 5\% DMEM supplemented with 5\% FBS at $37^{\circ} \mathrm{C}$ overnight. After incubation the cells were washed with cold PBS and lysed in $200 \mu \mathrm{l}$ of Reporter Lysis Buffer (Promega) containing a Roche protease inhibitor cocktail (\# P8349, Sigma-Aldrich), according to the manufacturer's instructions. Lysates were centrifuged for 15 minutes at $12,000 \mathrm{~g}$; total protein content in the protein supernatant was measured by the Bradford assay. Proteins were separated by Laemmli's electrophoresis in a $12 \%$ SDS-polyacrylamide gel, electrotransfer to a PVDF membrane (Amersham Hybond P $0.45 \mu \mathrm{m}$, Amersham Biosciences, GE Healthcare) was performed in Towbin transfer buffer $(25 \mathrm{mM}$ Tris, $192 \mathrm{mM}$ glycine, $20 \%$ (v/v) ethanol, $\mathrm{pH} 8.3)$. Membranes were blocked in a $4 \%$ solution of skim milk in PBST (PBS with $0.05 \%$
Tween 20) for 1 hour at room temperature. Incubation with primary and secondary (goat anti-rabbit IgGHRP, sc-2004, Santa Cruz Biotechnology) antibodies was performed overnight at $4^{\circ} \mathrm{C}$ and for 1 hour at room temperature, respectively. Immobilon Western Chemiluminescent HRP Substrate (Merck-Millipore, Sigma-Aldrich) was used for detection; the chemiluminescence signal was determined using the Bio-Rad ChemiDoc MP Imaging System (Bio-Rad). Quantification of protein bands was performed using ImageJ software (NIH, Bethesda, MD, USA). The following primary antibodies were used: $\beta$-actin (D6A8, \#8457, Cell Signaling Technology), LC3 (D11, \#3868, Cell Signaling Technology).

\section{Transcriptomic analysis}

\section{Sample preparation}

MRC5-SV40 cells were plated on $60 \mathrm{~mm}$ Petri dishes $\left(3 \times 10^{5}\right.$ cells per a dish) and cultured overnight at $37^{\circ} \mathrm{C}$ in DMEM supplemented with 10\% FBS. Next day, treatment with Abisil was carried out with concentrations of $5 \mu \mathrm{g} / \mathrm{ml}$ and $50 \mu \mathrm{g} / \mathrm{ml}$ in DMEM with 5\% FBS. Control samples were incubated in DMEM with 5\% FBS and $0.025 \%$ DMSO. After 16 hours, the medium was removed and the cells were washed with PBS, followed by lysis using $500 \mu \mathrm{l}$ of lysis buffer (MagNA Pure Compact RNA Isolation Kit, Roche). All treatment experiments were performed in triplicate.

\section{RNA isolation, preparation and sequencing of RNA- Seq libraries}

Total RNA was extracted using the RNeasy Mini kit (Qiagen, Germany) according to the manufacturer's protocol. The quality and quantity of RNA was determined using an Agilent 2100 bioanalyzer (Agilent Technologies, USA). RNA samples with RINs above 9.0 were used to prepare libraries. Total RNA $(2 \mu \mathrm{g})$ from each sample was used to prepare the mRNA library using the TruSeq RNA Sample Preparation Kit v2 Low Sample (LS) protocol (Illumina, USA) in accordance with the manufacturer's protocol. The cDNA libraries were sequenced (single end reads, $50 \mathrm{bp}$ ) using Illumina NextSeq 500 
system in the "Genome" Center (EIMB RAS, Russia, http://www.eimb.ru/rus/ckp/ccu_genome c.php).

\section{RNA-Seq data processing and differential expression analysis}

Raw reads were checked for quality and trimmed using the FastQC and Trimmomatic [18] tools. The trimmed reads were mapped to the human reference genome (GRCh38.80, Ensembl) with splice-aware STAR mapper [19]. Next, 5'-to-3' transcript read coverage distribution was evaluated using geneBody_coverage.py script from RSeQC package [20] in order to ensure the absence of 3 '-tail bias. Read counting per gene was done using featureCounts tool from the Subread package [21]. The further analysis was performed in $\mathrm{R}$ environment using edgeR (identification of differentially expressed genes), biomaRt (annotation), topGO and clusterProfiler (GO, KEGG, Reactome enrichment analyses), pathview (visualization) and other packages.

\section{Proteomic analysis}

\section{Sample preparation}

The MRC5-SV40 line was also used for panoramic proteomic analysis. $3 \times 10^{5}$ cells were plated on $60 \mathrm{~mm}$ Petri dishes. After a night of incubation in the complete medium 16-hour treatment with Abisil at concentration of $50 \mu \mathrm{g} / \mathrm{ml}$ in DMEM medium with $5 \%$ FBS was performed. Control samples were treated with DMEM with 5\% FBS and $0.025 \%$ DMSO. After 16 hours the medium was removed and the cells were washed twice with PBS, then the cells were removed from the dishes in $800 \mu 1$ PBS using a scraper.

The sample preparation for proteomic analysis was performed using Pierce Mass Spec Sample Prep Kit (Thermo Fisher Scientific, MA, USA) [22]. In addition, Thermo Scientific Pierce Digestion Indicator from the same kit, was used to assess the digestion reproducibility for multiple samples. For sample preparation $1 \times 10^{6}$ cells (100 $\mu \mathrm{g}$ of protein) were lysed using modified radioimmunoprecipitation assay buffer (RIPA), which was followed by reduction step using $2 \mathrm{M}$ dithiothreitol for $45 \mathrm{~min}$ at $50^{\circ} \mathrm{C}$. For alkylation step iodoacetamide was added to the sample (final volume $50 \mathrm{mM}$ ) and incubated at room temperature for $20 \mathrm{~min}$. Immediately after incubation 4 volumes (460 $\mu \mathrm{l})$ of pre-chilled $\left(-20^{\circ} \mathrm{C}\right) 100 \%$ acetone was added to samples. Two-step enzymatic protein digestion was performed using Lys-C (enzyme-to-substrate ratio = $1: 100,37^{\circ} \mathrm{C}$ for 2 hours) and trypsin (enzyme-tosubstrate ratio $=1: 50,37^{\circ} \mathrm{C}$ for 17 hours). To remove the digestion buffer samples were dried at the SpeedVac and resuspended in $0.1 \%$ TFA buffer. Protein concentration was measured using bicinchoninic acid assay (BCA assay) [23].

\section{$L C-M S / M S$}

LC-MS/MS was performed using an TIMS TOF Pro mass spectrometer (Bruker Daltonics, USA) combined with an UltiMate 3000 nano LC system (Thermo Fisher Scientific, MA, USA). The amount of loaded sample was $100 \mathrm{ng}$ per injection. The tryptic peptide fraction (injection volume $1 \mu \mathrm{L}$ ) was analyzed in triplicate on a Dionex UltiMate 3000 Nano HPLC System (Thermo Fisher Scientific, MA, USA) coupled to a TiMS TOF mass spectrometer (Bruker Daltonics, Bremen, Germany) using a captive spray ion source (positive ion mode, 1600 V) (Bruker Daltonics, Bremen, Germany). HPLC separation was performed on a C18 capillary column $(25 \mathrm{~cm} \times 75 \mu \mathrm{m} 1.6 \mu \mathrm{m})$ (Ion Optics, Parkville, Australia) by gradient elution. The mobile phase A was $0.1 \%$ formic acid diluted in water and mobile phase B was $0.1 \%$ formic acid diluted in acetonitrile. The separation was carried out by a 120 -min gradient from $4 \%$ to $90 \%$ of phase $\mathrm{B}$ at a flow rate of 0.4 $\mu \mathrm{L} /$ min. Mass-spectrometric measurements were carried out using Parallel Accumulation Serial Fragmentation (PASEF) acquisition method. The measurements were carried out in $\mathrm{m} / \mathrm{z}$ range from 100 to 1700 . The range of ion mobility include a value from $0.60-1.60 \mathrm{Vs} / \mathrm{cm} 2(1 / \mathrm{k} 0)$. The number of precursor ions per one PASEF cycle $(1.2 \mathrm{sec})$ was 10 . Low abundant precursor ions can be analyzed multiple times during PASEF cycle.

\section{Protein identification and quantification}

For label-free analysis the obtained MS spectra were processed with MaxQuant software against the SwissProt 2018 database [24]. Oxidation of methionine and acetylation of N-terminal were selected as variable modification. Minimal length for peptide identification was seven amino acids and at least one peptide should be unique for a protein. False discovery rate (FDR) threshold for proteins and peptides was set 0.01 . Additionally, match between the runs option were used.

\section{Identification of altered proteins}

Protein quantification was carried out using label free quantitation intensities (LFQ) based on relative protein quantification across all samples and represented by a normalized intensity profile that is generated according to the algorithms described by Cox, J. et al. [25]. Statistical processing of proteomic data was performed in $\mathrm{R}$ environment. Two samples Welch's t-test was applied to identify the significantly altered proteins between treated and control groups. Correlation between proteins composition in technical runs was estimated using Pearson's correlation analysis for log-transformed abundance values (the values of correlation coefficient were about 0.9). 


\section{Pathway enrichment analysis}

Differentially regulated proteins were divided into several groups for the pathway enrichment analysis: (1) upregulated: FDR $<0.05$ (Welch's t-test), two-fold ore greater fold change; (2) downregulated: FDR < 0.05 , twofold ore greater fold change; (3) a group of marginally altered proteins with FDR $<0.05$ and fold change less than two-fold. Each protein group was analyzed separately for GO enrichment. Protein interaction network analysis was done using STRINGdb [26]. The results of GO enrichment analysis was grouped by semantic similarity using the REVIGO tool [27].

\section{Data availability}

Transcriptome sequencing data are available at NCBI SRA portal (BioProject identifier PRJNA642179).

\section{RESULTS}

\section{Cytotoxicity of different concentrations of Abisil}

The effect of 48-hour treatment with Abisil on the metabolic activity of cells was studied using the MTS assay on human embryonic lung fibroblast lines (MRC5-SV40 and LECH-4). Abisil demonstrated significant dose dependence (Figure 1). The calculated IC50 values were $149.3 \pm 0.67$ for MRC5-SV40 and $152.6 \pm 0.52 \mu \mathrm{g} / \mathrm{ml}$ for LECH-4, respectively (Table 2). In addition, both cell lines showed a significant increase in metabolic activity ( $p$-value $<0.001$ ) when treated with the low drug concentrations $(9-15 \mu \mathrm{g} / \mathrm{ml})$.

\section{Antioxidant activity of Abisil}

After a series of experiments, DHE staining method (described in the materials and methods) was chosen as optimal approach to evaluate the levels of ROS after treatment with Abisil in a wide concentration range.

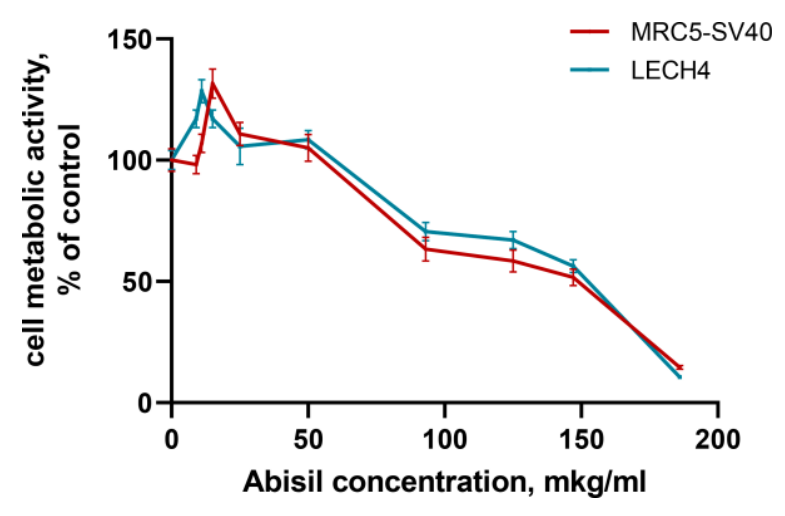

Figure 1. Assessment of the metabolic activity of cells treated with various concentrations of Abisil (MTS assay).
This method demonstrated good reproducibility (range of variation $10-25 \%)$.

The diagram on the Figure 2 shows the ROS levels assessment results after a 16-hour treatment with Abisil in the range of concentrations $25-125 \mu \mathrm{g} / \mathrm{ml}$.

The results demonstrate that the most intense decrease in ROS after induction by rotenone is observed for concentrations of 25 and $50 \mu \mathrm{g} / \mathrm{ml}$ (Figure 2). It is worth noting that there is a significant prooxidant effect at higher concentrations of the drug $(125 \mu \mathrm{g} / \mathrm{ml})$. There is also a tendency towards a decrease in ROS in the absence of inductor.

\section{Abisil causes decrease in mitochondrial potential}

As Abisil downregulates genes encoding for subunits of the respiratory complex I (according to RNA-Seq data; described below; Supplementary Figure 2), it was tested if Abisil might cause the decrease of mitochondrial potential. Indeed, Abisil treatment induced more than 2 times-fold drop of mitochondrial potential (p-value < 0.01, Mann-Whitney U-test; Figure 3). As a positive control, we used carbonyl cyanide chlorophenylhydrazone (CCCP). This is a lipidsoluble weak acid, mitochondrial toxin and a potent mitochondrial uncoupling agent. It increases the proton permeability across the mitochondrial inner membrane, thus dissipating the transmembrane potential and depolarizing the mitochondria.

\section{Abisil treatment results in intense autophagy after 24 hours}

Autophagy was assessed by the amount of LC3II in MRC5-SV40 cells by western blotting (Figure 4A). Figure 4B shows the results of LC3II densitometric analysis with respect to internal control (beta-actin) which are presented as mean \pm standard deviation calculated from three independent experiments. There is a significant increase in the content of LC3II complexes (more than 10-fold) when treated with Abisil at concentration of $50 \mu \mathrm{g} / \mathrm{ml}$, which shows effective stimulation of autophagy.

To carry out an accurate quantitative assessment of the effectiveness of autophagy, a 3D reconstruction of a set of fields was carried out using a z-stack approach on a confocal microscope. 20 fields were used for each of sample type: control (0.5\% DMSO), treated with Abisil $50 \mu \mathrm{g} / \mathrm{ml}$, treated with chloroquine $50 \mu \mathrm{M}$ and treated with both Abisil and chloroquine). An example of the images obtained is shown below (Figures 5, 6). Data on the number of large autophagosomes are shown in the diagram (Figure 7). As you can see 
Table 2. Cytotoxic effect of Abisil.

\begin{tabular}{lcccc}
\hline Cell line & IC50, $\boldsymbol{\mu g}$ /ml & $\begin{array}{c}\text { Metabolic activity } \\
\text { normalized to } \\
\text { control, \% }\end{array}$ & $\begin{array}{c}\text { Concentration of the drug, } \\
\text { causing the maximum } \\
\text { metabolic rate, } \boldsymbol{\mu g} / \mathbf{m l}\end{array}$ & $\begin{array}{c}\text { Metabolic activity } \\
\text { normalized to } \\
\text { control, \% }\end{array}$ \\
\hline $\begin{array}{l}\text { Embryonic lung fibroblasts } \\
\text { immortalized with SV40 } \\
\text { (MRC5-SV40) virus }\end{array}$ & $149.3 \pm 0.7$ & 50 & 15 & 131.5 \\
$\begin{array}{l}\text { Primary embryonic pulmonary } \\
\text { fibroblasts (LECH-4) }\end{array}$ & $152.6 \pm 0.5$ & 50 & 11 & 128.2 \\
\hline
\end{tabular}

Evaluating cell metabolic activity with MTS assay.

below, autophagy is induced efficiently in 24 hours after treatment.

\section{Abisil does not increases the level of mitophagy and doesn't affect the number of mtDNA copies}

The decrease of mitochondrial potential caused by Abisil treatment might imply that Abisil induces mitophagy [2830]. In order to verify this hypothesis, MRC5-SV40 cells were treated with Abisil and tested whether Mitotracker Red colocalized with Lysotracker Green (Figures 8, 9). There was an increase of the number of phagolysosomes, but they did not colocalize with Mitotracker Red indicating that Abisil promotes autophagy but does not specifically induce mitophagy in SV40 transformed MRC5. The same treatment was conducted on LECH-4 cells with the same result (data not shown).

Changes in mitochondrial potential detected in previous experiments suggested to test also the copy number of mitochondria DNA. As can be seen from the diagram in Figure 10, the amount of mitochondrial DNA did not change at all.

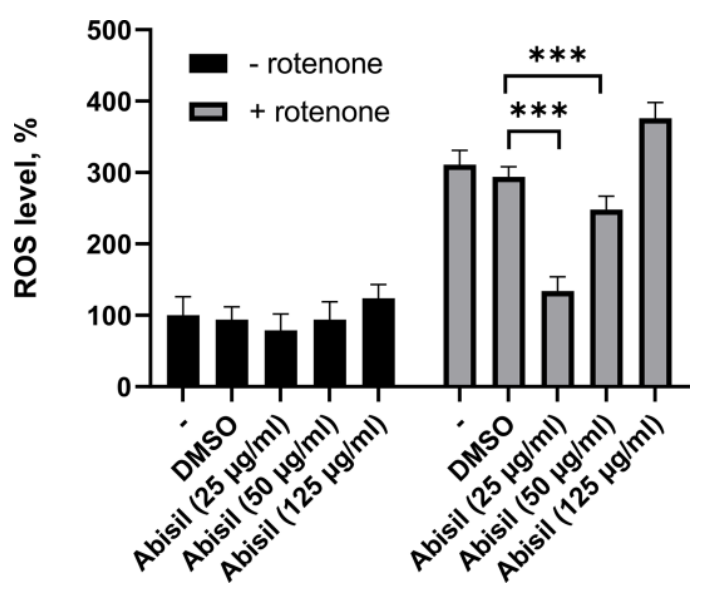

Figure 2. ROS levels assessment in MRC5-SV40 cells treated with various concentrations of Abisil. ${ }^{* * *} p<0.001$ (t-test).

\section{Abisil induce changes in cell energy metabolism}

Using the Seahorse XF-24 extracellular flux analyzer, we analyzed changes in mitochondrial respiration and glycolysis rates after between Abisil-treated and control cells. The results are presented at the Figure 11. While the rate of oxygen consumption drops slightly, the glycolytic activity is significantly reduced. Thus, we see that both the current activity of glycolysis and its maximum rate, possible for the cell (glycolytic capacity), decrease proportionally.

\section{Transcriptomic changes induced by Abisil treatment}

We performed RNA-Seq analysis for MRC5-SV40 cells treated with Abisil at concentrations 5 and 50 $\mu \mathrm{g} / \mathrm{ml}$ as well as control cells (Supplementary Tables 1-4). Taken at both concentrations, Abisil treatment induced vast transcriptomic shift spanning several thousand genes. The effect of treatment with both concentrations was generally similar (see the Supplementary Figure 3). Surprisingly, at a concentration of $5 \mu \mathrm{g} / \mathrm{ml}$, the effect was even more

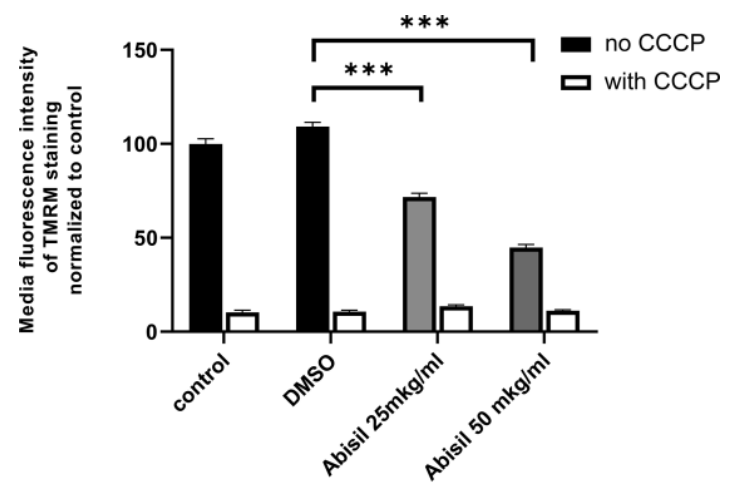

Figure 3. Abisil causes decrease in mitochondrial potential in immortalized MRC5 cells. MRC5-SV40 cells were incubated with Abisil $(25 \mathrm{mkg} / \mathrm{ml}$ and $50 \mathrm{mkg} / \mathrm{ml}$ ) overnight and stained with TMRM, and fluorescence of the stain was measured in PE channel. The black bars represent Abisil-treated cells; the grey bars represent control cells. $* * * p<0.001$ (t-test). 
A

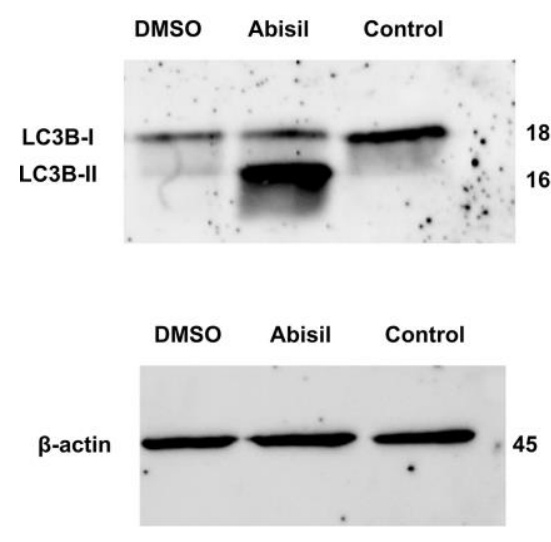

B

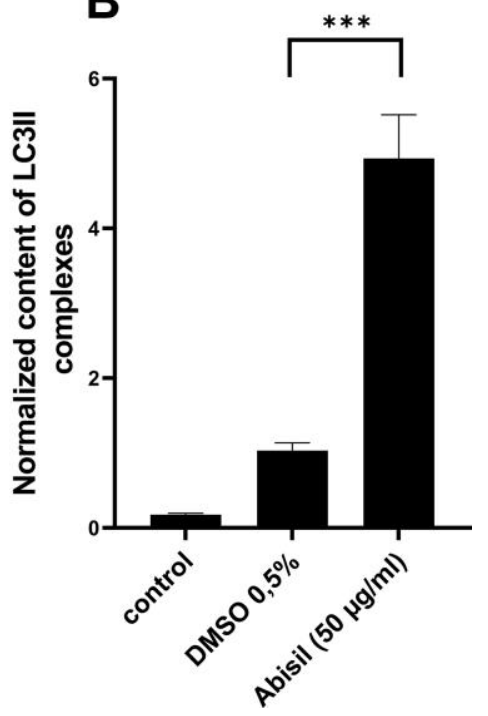

Figure 4. Effect of Abisil pretreatment on LC3II accumulation in MRC5-SV40. (A) Western blot analysis of LC3 protein. (B) densitometric analysis results of LC3II normalized to endogenous control (beta-actin). ${ }^{* * *} p<0.001$ ( $t$-test).
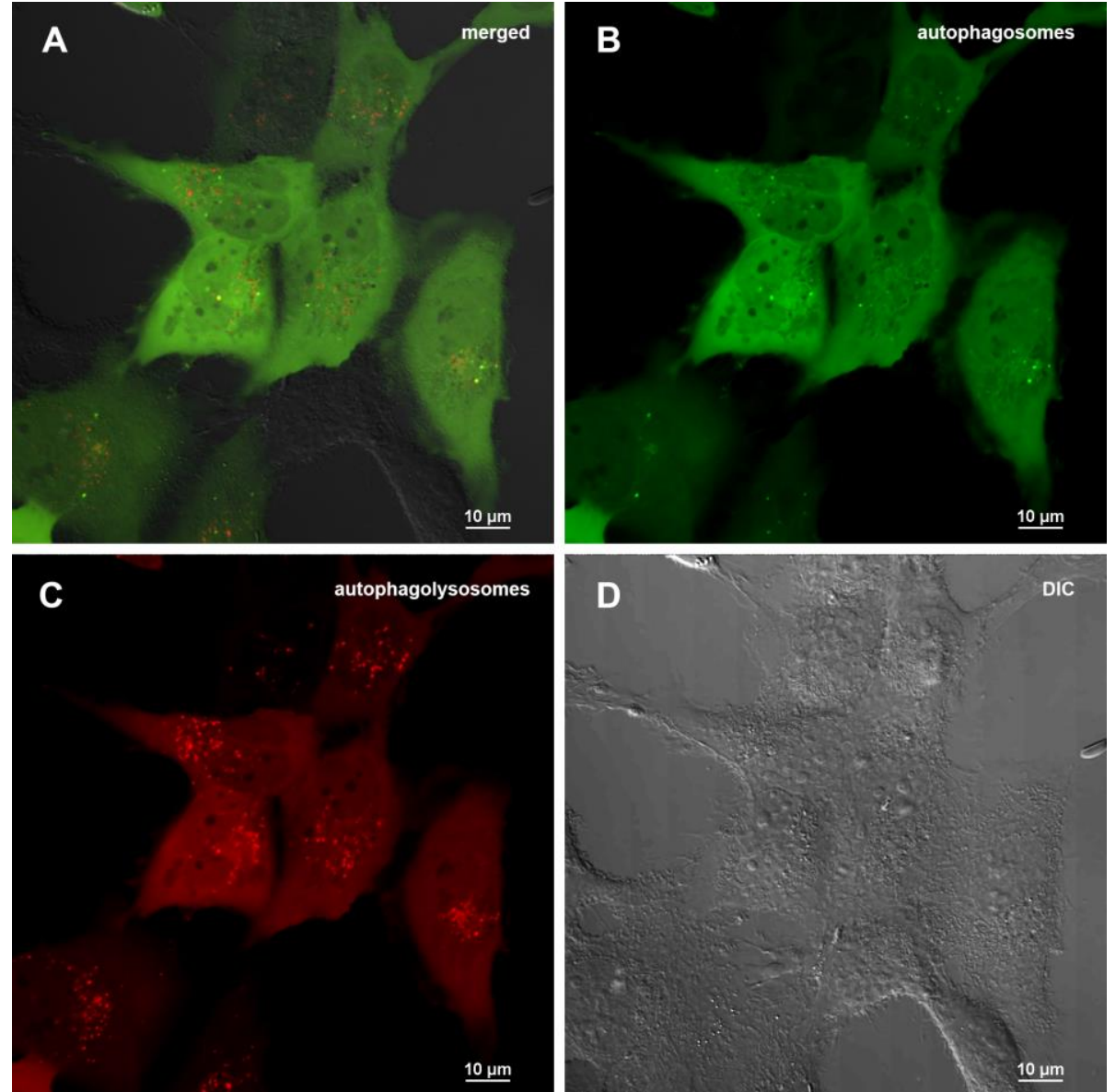

Figure 5. Assessment of autophagy in MRC5-SV40 cells carrying GFP-LC3-mCherry reporter (control sample) when treated with DMSO $\mathbf{0 . 5 \%}$ after 24 hours. (A) merge of red, green fluorescence channels and bright field, (B) green fluorescence channel, (C) red fluorescence channel, (D) bright field. 

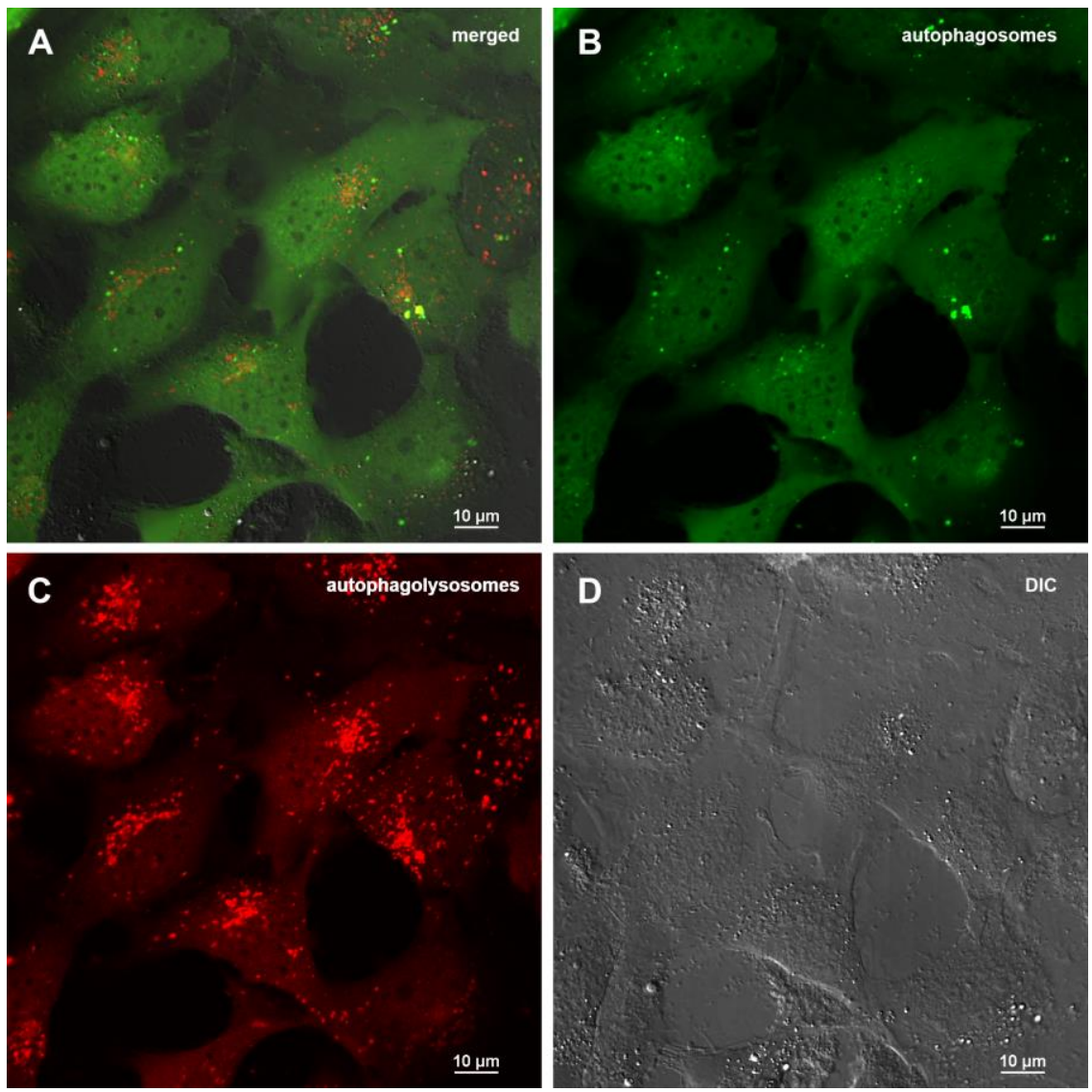

Figure 6. Assessment of autophagy in MRC5-SV40 carrying GFP-LC3-mCherry reporter when treated with $50 \mu \mathrm{g} / \mathrm{ml}$ Abisil after 24 hours. (A) merge of red, green fluorescence channels and bright field, (B) green fluorescence channel, (C) red fluorescence channel, (D) bright field.
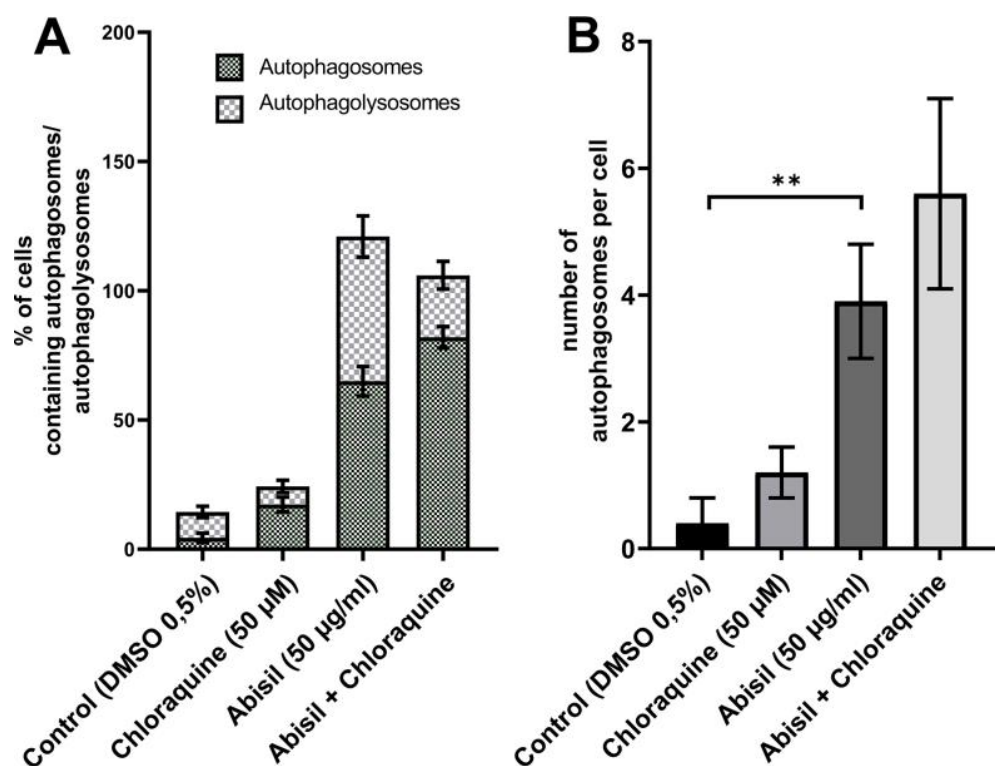

Figure 7. Assessment of autophagy in MRC5-SV40 carrying GFP-LC3-mCherry reporter when treated with Abisil $(50 \mu \mathrm{g} / \mathrm{ml})$ in presence or absence of chloroquine $(50 \mu \mathrm{M})$ after 24 hours. (A) percentage of cells containing autophagosomes, (B) number of autophagosomes per cell. ${ }^{* *} p<0.01$ (t-test). 
pronounced. In this case, 2075 genes passed FDR < 0.05 threshold and had at least 1.5-fold expression level changes. We noted a predominant decrease in expression. So, among the top 200 differentially expressed genes (DEGs), 189 were downregulated. The lists of DEGs between 5 and $50 \mu \mathrm{g} / \mathrm{ml}$ significantly overlapped. The spectra of enriched Gene Ontology terms also overlapped. At both concentrations of Abisil, the lists of downregulated DEGs were strongly enriched with genes involved in cell cycle and related processes. In addition, we noted overrepresentation of genes involved in mRNA processing, protein folding, fatty acid elongation, NIK/NF- $\kappa \beta$ and WNT signaling, antigen processing and presentation, cellular response to hypoxia.

Among biological processes, participants of which were overrepresented in upregulated genes, we noticed Notch signaling pathway, positive and negative regulation of apoptotic process, heterocycle catabolic process and other processes. We noticed bidirectional expressional changes of genes encoding for ribosomal proteins, but it is hard to say about the prevalence of any direction.

Interestingly, KEGG enrichment analysis revealed significant overrepresentation of downregulated DEGs among participants of oxidative phosphorylation, DNA replication process, basal transcription factors, spliceosome subunits, proteasome subunits (for both Abisil concentrations). Figure 12 shows the transcriptomic effect of Abisil treatment on genes involved in several mostly affected KEGG pathways. For a more detailed info, see the Supplementary Table 9.

The comparison of samples treated with different Abisil concentrations ( 5 and $50 \mu \mathrm{g} / \mathrm{ml}$ ) revealed 1281 genes that passed FDR $<0.05$ threshold, but only 305 of them had 1.5-fold or greater expression level changes. The lists of DEGs demonstrated enrichment in genes involved in the regulation cell proliferation and growth, cytoskeleton organization, RNA splicing, cell
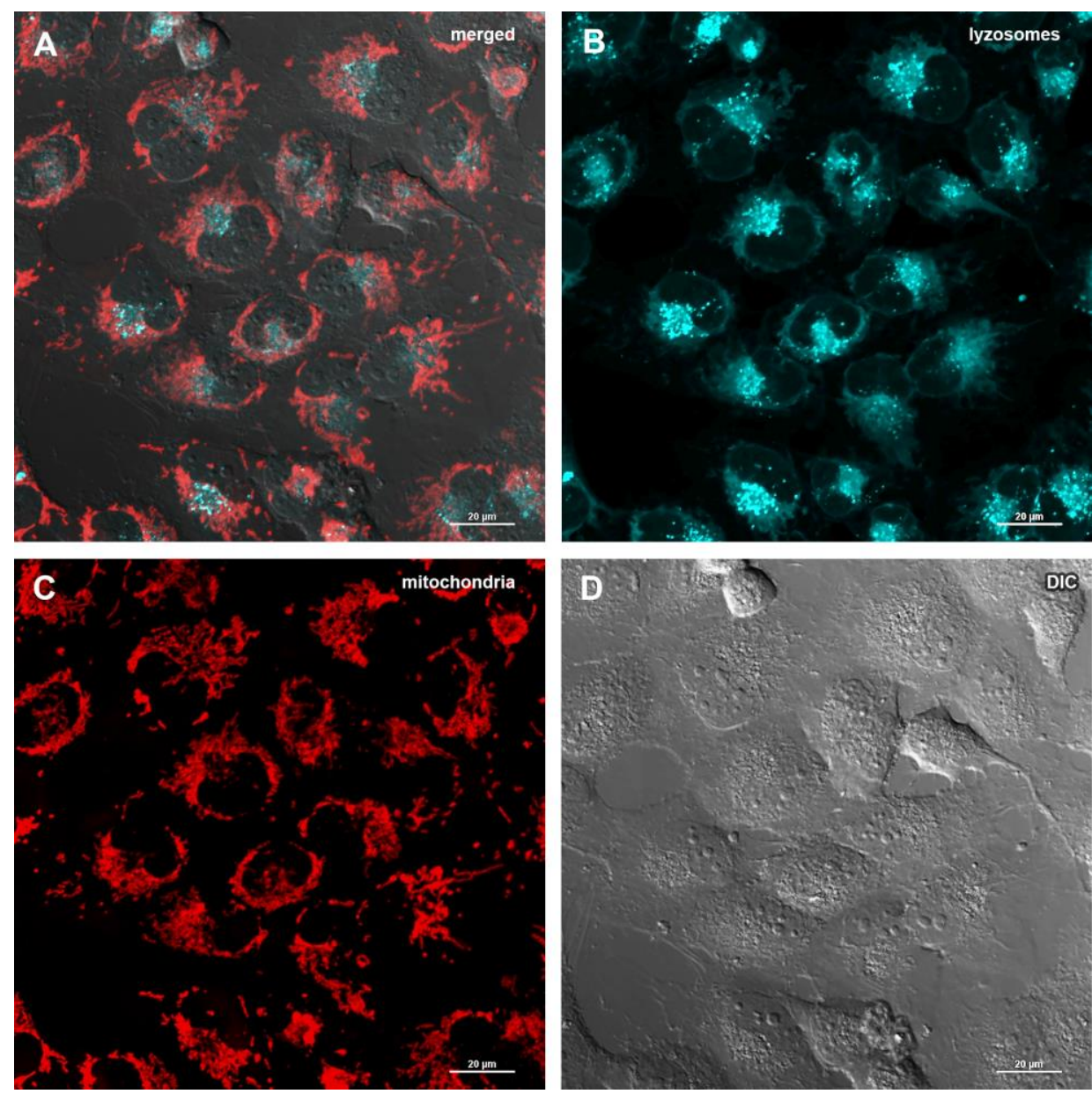

Figure 8. Assessment of mitophagy in MRC5-SV40 cells when treated with DMSO $0.5 \%$ for 24 hours. (A) merge of red, green fluorescence channels and bright field, (B) green fluorescence channel, (C) red fluorescence channel, (D) bright field. 
metabolism, including biosynthesis of amino acids, chemotaxis and cell adhesion, extracellular matrix organization, ion transport. The complete results of GO enrichment analyses are presented in the Supplementary Tables 5-8.

Mainly, the effect of Abisil on biological processes and cellular pathways can be described as: 1) suppressing genes participating in oxidative phosphorylation, DNA replication (especially at low Abisil concentrations), mRNA transcription and splicing, RNA transport, fatty acid biosynthesis, protein export, proteolysis; 2) activating phosphatidylinositol signaling, cytosolic DNA-sensing pathway, PPAR signaling pathway, various pathways involved in the immune response; 3 ) bidirectional impact on cell cycle (predominantly, downregulation) and endocytosis.
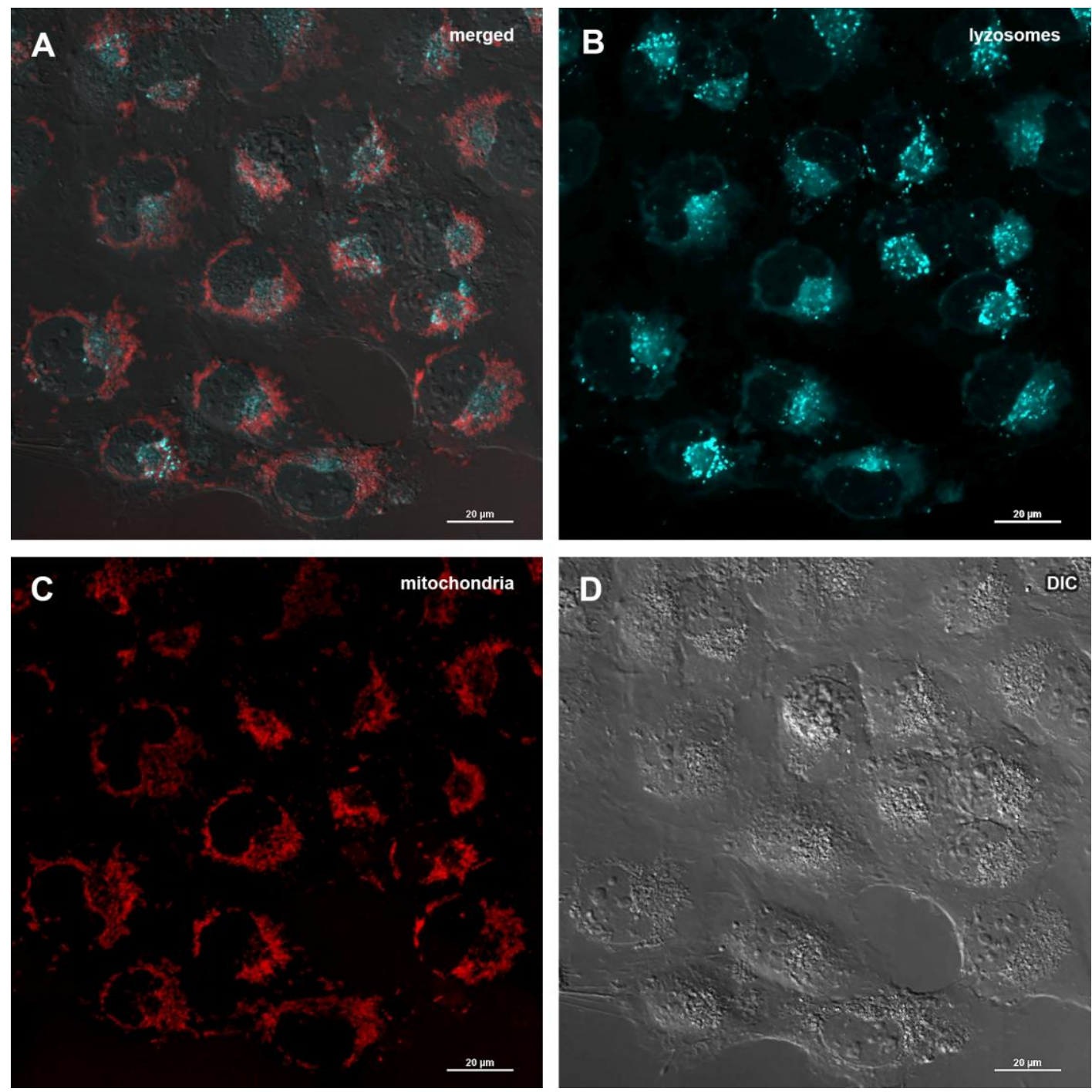

Figure 9. Assessment of mitophagy in MRC5-SV40 cells when treated with Abisil at concentration of $\mathbf{5 0} \mu \mathrm{g} / \mathrm{ml}$ for $\mathbf{2 4}$ hours. (A) merge of red, green fluorescence channels and bright field, (B) green fluorescence channel, (C) red fluorescence channel, (D) bright field. 
mitochondrial potential itself (see the Figure 3), but also reduces the expression of genes participating oxidative phosphorylation. (Supplementary Figure 2) Taken at both concentrations, it causes a decrease in the expression mainly for genes of the mitochondrial genome: NADH dehydrogenase (ND1-6) and cytochrome C oxidase (COX1-3). Expression levels of genes from the cell nuclear genome, whose products are involved in oxidative phosphorylation (NDUFA, NDUFB, succinate dehydrogenase, ATPase), are altered to a much lesser extent. Both up- and downregulations are noted mainly for treatment with high concentration of Abisil (Supplementary Figure 2).

Worth noting, Abisil treatment results in predominant downregulation of many genes encoding for kinases and kinase-associated proteins (KKPs; containing "kinase" keyword in a gene name). Among top 50 differentially expressed KKPs after treatment with Abisil at $5 \mu \mathrm{g} / \mathrm{ml}$, 35 are downregulated, and the average $\log 2$ (fold change) for all these 50 genes is -0.45 . The concentration $50 \mu \mathrm{g} / \mathrm{ml}$ gives less pronounced result.

Thus, such effect is more pronounced for low concentration of the drug $(5 \mu \mathrm{g} / \mathrm{ml})$. Moreover, we noticed that 27 of $30(90 \%)$ KKPs downregulated after $50 \mu \mathrm{g} / \mathrm{ml}$ treatment (FDR < 0.05) lies within the list of 70 downregulated KKPs after $5 \mu \mathrm{g} / \mathrm{ml}$ treatment (FDR < 0.05). These 27 KKPs are: BUB1, MAP2K4, MNAT1, $L Y N, A X L, J A K 1, C S N K 2 A 2, A K 6, T A B 2, S N R K, A K 3$, CLK1, DYRK1A, CDKN3, CDK6, FASTKD3, SH3KBP1, PRKACB, MOB1B, TTK, PXK, MAP3K20, PRKRA, RPS6KC1, PRKD3, NRK, PIK3R1.

Figure 14 illustrates the results of the protein-protein interaction network analysis for top 200 genes that are downregulated after Abisil treatment $(5 \mu \mathrm{g} / \mathrm{ml})$. We can see several net modules, that are responsible for translation, mRNA processing, regulation of cell cycle and other activities. Even though Abisil stimulates autophagy (as demonstrated above), however, at the transcriptome level, we do not see a consistent and unidirectional change in the expression of genes involved in autophagy, mTOR and AMPK signaling.

\section{Analysis of panoramic proteomic sequencing results}

Large-scale quantitative proteome profiling was performed to reveal differentially expressed proteins in MRC5-SV40 cells treated with Abisil $(50 \mu \mathrm{g} / \mathrm{ml})$ compared to non-treated ones. Total 4906 proteins have been detected either for treated or non-treated cells. As it was noticed for transcriptome profiling, we observed that Abisil treatment mainly induces downregulation of expression. 4002 proteins were detected in non-treated MRC5-SV40 cells and only 3068 in Abisil-treated
(2164 proteins were detected in both conditions). The detailed data on the proteome profiling is presented in the Supplementary Table 10.

Gene Ontology, KEGG and Reactome overrepresentation analysis revealed that the list of top 300 down-regulated proteins is enriched with participants of cell cycle regulation, exocytosis, secretion. Both lists, top 300 down- and top 300 up-regulated proteins were highly enriched with participants of RNA processing, translation, mitochondrial organization, oxidative phosphorylation, cell metabolism, transport, gene expression regulation, histone modification, membrane trafficking, ER to Golgi anterograde transport, and many other biological processes.

Protein-protein interaction (PPI) networks for down- and up-regulated proteins is presented in the Supplementary Figures 4, 5. Both networks are highly enriched with PPIs $\left(\mathrm{p}<10^{-16}\right.$ ) according to the STRING database analysis results. We can see that proteins, participating in translation, mitochondrial organization, RNA processing, form compact subnets (marked with colors), whereas proteins involved in cell metabolism and intracellular transport are spread over the whole network.

To sum up the analysis, it is possible to conclude that the content of many proteins in the cell decreases (possibly, because of autophagy) after Abisil treatment. The expression of genes/proteins, involved in translation, mitochondrial organization, gene expression regulation, cell metabolism and transport, is significantly altered (either down- or upregulated).

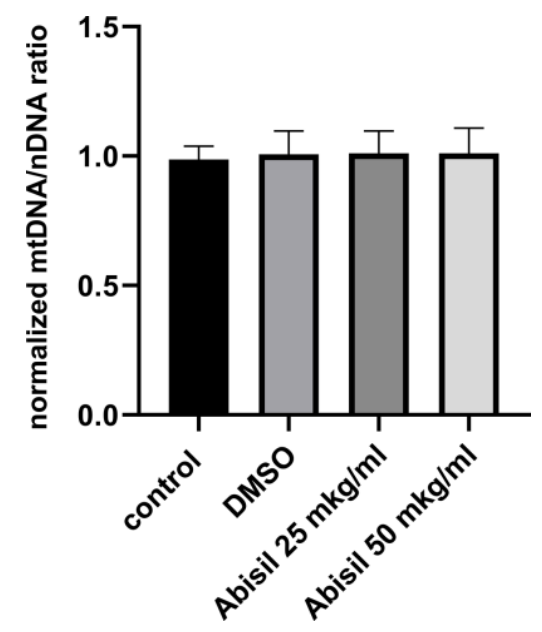

Figure 10. Relative mitochondrial copy number determined by GPCR in MRC5-SV40 cells, untreated (control), treated with DMSO or Abisil (16 hours after treatment). The mtDNA/nDNA copy number ratio was normalized to DMSO treated samples. 
It is remarkably that the content of such proteins as mTOR, RICTOR (Rapamycin-insensitive companion of mTOR), Cytochrome c, RBL1 (Retinoblastoma-like protein 1), Ras-related protein Rab-13, TGF-beta receptor type-1 (TGFBR1), Tumor necrosis factor receptor superfamily member 12A (TNFRSF12A), Cyclin-dependent kinase 9 (CDK9), Mitogen-activated protein kinases (MAPK14, MAP3K6, MAP3K2, MAPK8, MAPK3, MAP4K5, MAPK14) and Renin receptor (ATP6AP2) was significantly reduced (or even not detected by MS) after treatment with Abisil. However, the expression of some MAPKs (MAP4K4, MAP3K7, MAPK9, ZAK, MAPK1) was upregulated (or was detected only in non-treated cells).

\section{DISCUSSION}

Terpenoids are undeservedly neglected in the study of geroprotective properties, except for carotenoids only
[31]. At the same time, it is well documented that limonene [32], dibornol [33], betulinic [34], ursolic, and oleanolic acids [35] have some potential properties for preventing or alleviating diseases associated with aging.

Previously it was revealed that natural conifer terpenoids demonstrate anti-proliferative, pro-apoptotic activity and have anti-angiogenic potential. [17]. Earlier, we also investigated in vitro anti-aging and anti-cancer properties of Abisil, a complex mixture of diterpene and triterpene acids and esters with cyclic and acyclic monoterpenes from natural extract of Siberian fir [16]. We have shown that it restores the expression level of some prolongevity genes in old cells, including those involved in MAPK-, FOXO- and HIF-1 signaling pathways. In the present work we focused on the assessment of metabolic and cellular effects of Abisil, including mitochondrial function, autophagy whole transcriptome and proteome profiling.

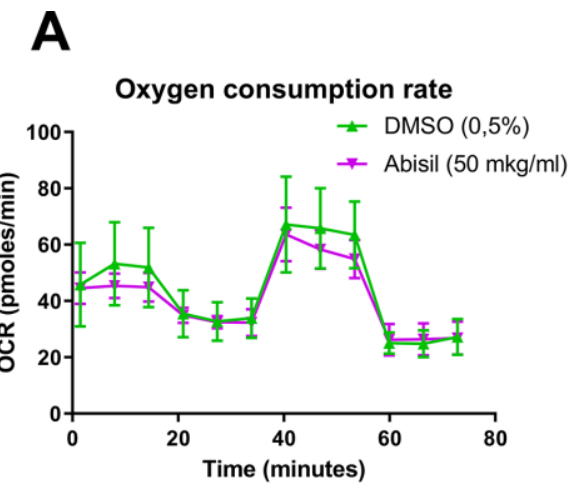

\section{B}
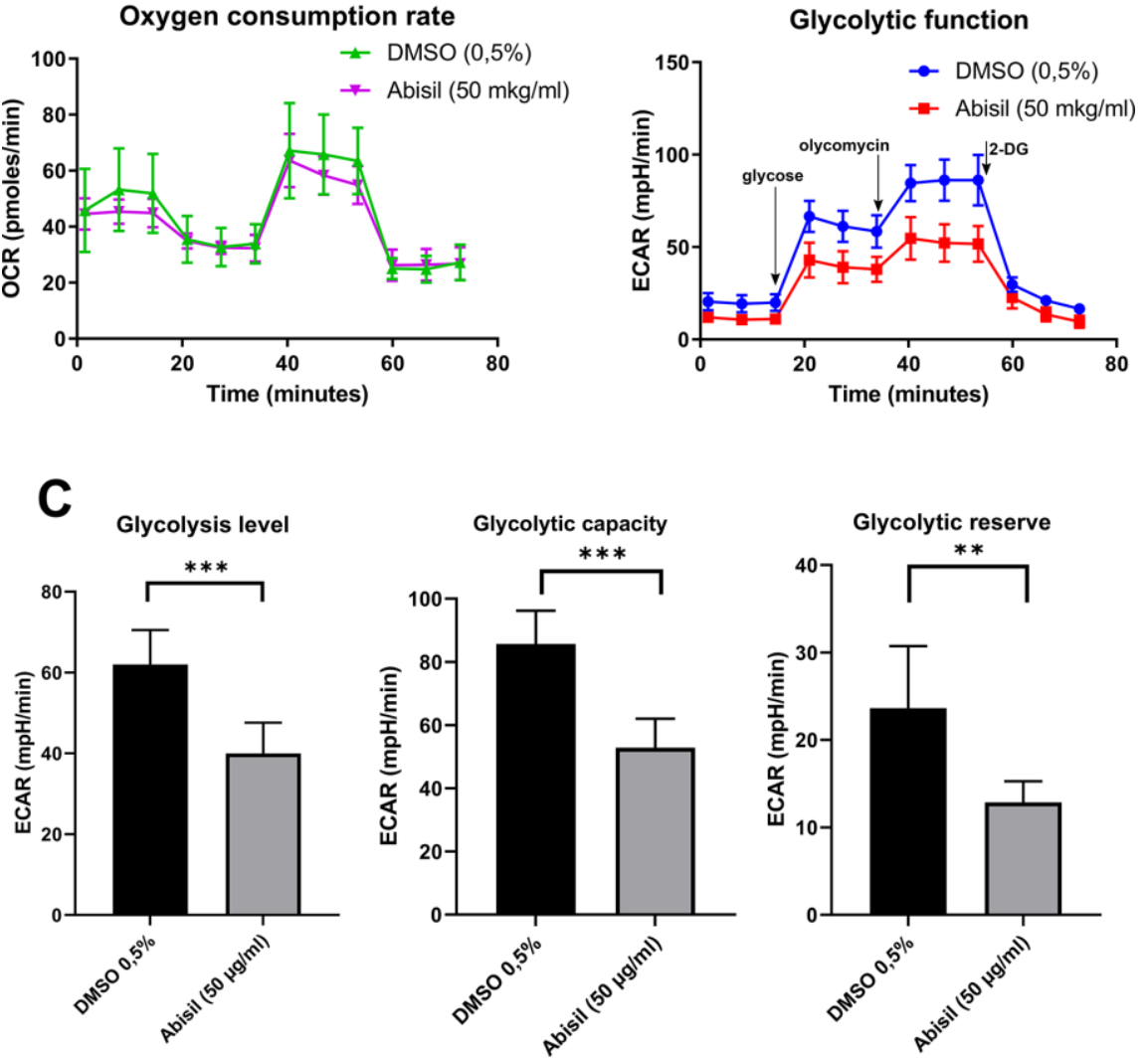

Figure 11. Changes in mitochondrial respiration and glycolysis level of MRC5-SV40 cells after Abisil treatment. (A) After 16 hours of Abisil treatment, mitochondrial respiration reflected by the level of oxygen consumption rate (OCR) in control (DMSO 0.5\%) or Abisil $(50 \mu \mathrm{g} / \mathrm{ml})$ groups ( $\mathrm{n}=4$ per group), following the injection of oligomycin, FCCP and antimycin A/rotenone. (B) the extracellular acidification rate (ECAR) of the medium following injection of glycose, oligomycin and 2 desoxyglucose. (C) The rates of glycolysis level, glycolytic capacity and glycolytic reserve ( $n=4$ per group). Bars represent mean values with SD, $* * p<0.01, * * * p<0.001$ ( $t$-test). Glycolytic level - the basal rate of conversion of glucose to pyruvate/lactate; glycolytic capacity - the maximal rate of glycolysis that can be rapidly achieved by a cell; glycolytic reserve - the difference between the glycolytic capacity and the basal glycolytic rate. 
Mitochondrial function relies on mitochondrial quality control and homeostasis. Mitohormesis is a process in which low, non-cytotoxic concentrations of reactive oxygen species promote mitochondrial homeostasis [36]. At a hormesis a dose response has either J-shape or an inverted U-shape dependency [37]. Exposure to low doses leads to protective and favorable reactions, while exposure to high doses is disruptive and harmful.
[38]. There are several observations that confirm stimulation effects of Abisil at small doses. As shown in the present paper, while in low concentration Abisil had an antioxidant effect and at a higher concentration it had a prooxidant action. In addition, treatment of embryonic pulmonary fibroblast cell lines with Abisil revealed a dose-dependent metabolic activation, evaluated using the MTS test.

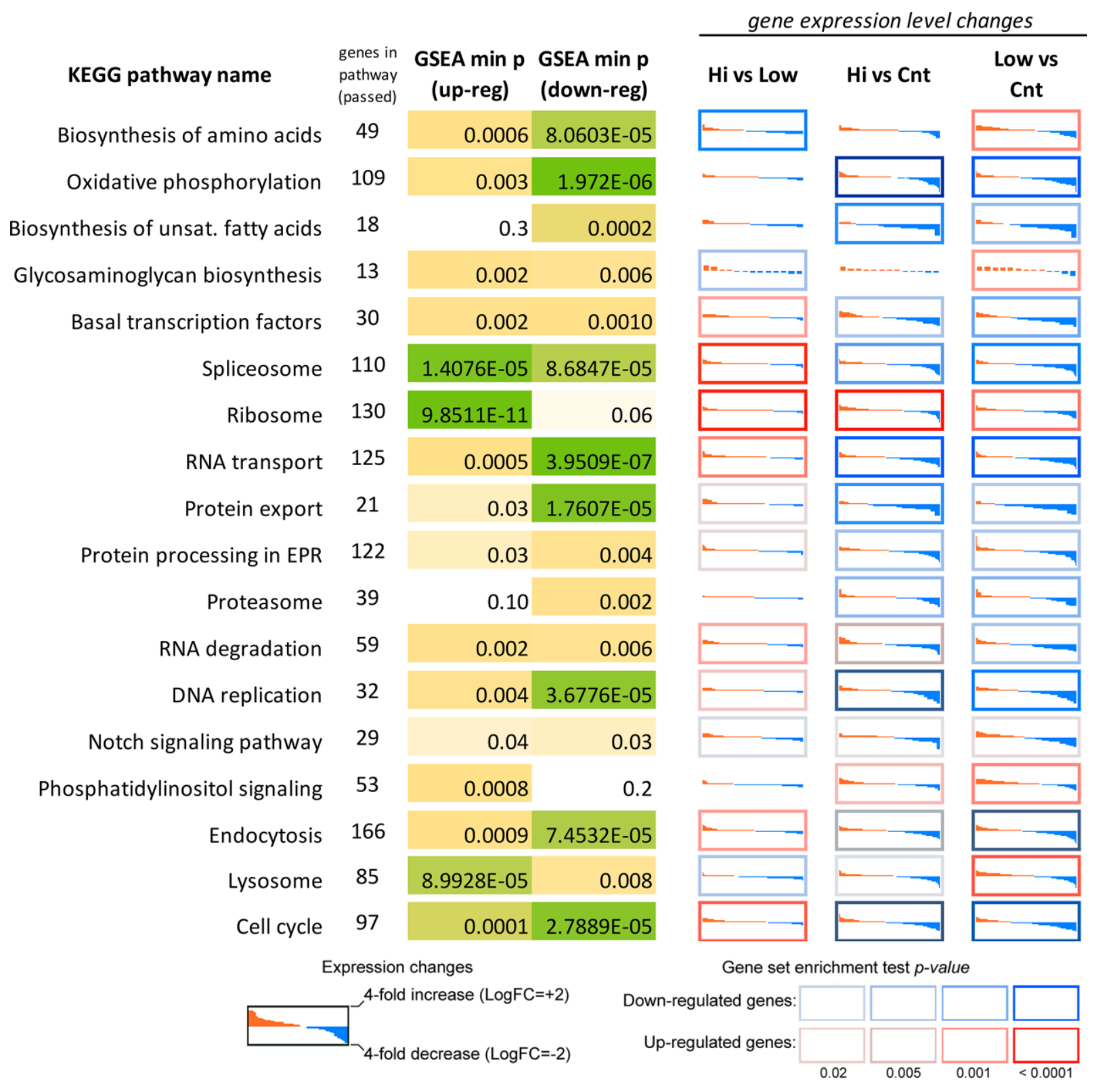

Figure 12. Differential expression profiles of genes participating mostly affected KEGG pathways according to the RNA-Seq data for MRC5-SV40 cell line treated with Abisil. Each cell demonstrates the sorted expression level log fold changes after Abisil treatment (red - upregulation, blue - downregulation) for genes participating a current KEGG pathway (vertical axis range is from 4-fold downregulation to 4-fold upregulation). Cell borders indicate whether a pathway is enriched with up- (red border) or downregulated (blue border) genes. GSEA min $p$ (up/down-reg) - minimal p-value in a gene set enrichment analyses (GSEA; Fisher's exact test) for the pathway. Hi vs Low - comparison of cells treated with 50 and $5 \mu \mathrm{g} / \mathrm{ml}$; Hi vs Cnt - comparison of cells treated with Abisil $50 \mu \mathrm{g} / \mathrm{ml}$ and non-treated cells; Low vs Cnt - comparison of cells treated with Abisil $5 \mu \mathrm{g} / \mathrm{ml}$ and non-treated cells. 
A Abisil $5 \mu \mathrm{g} / \mathrm{ml}$ compared to non-treated cells

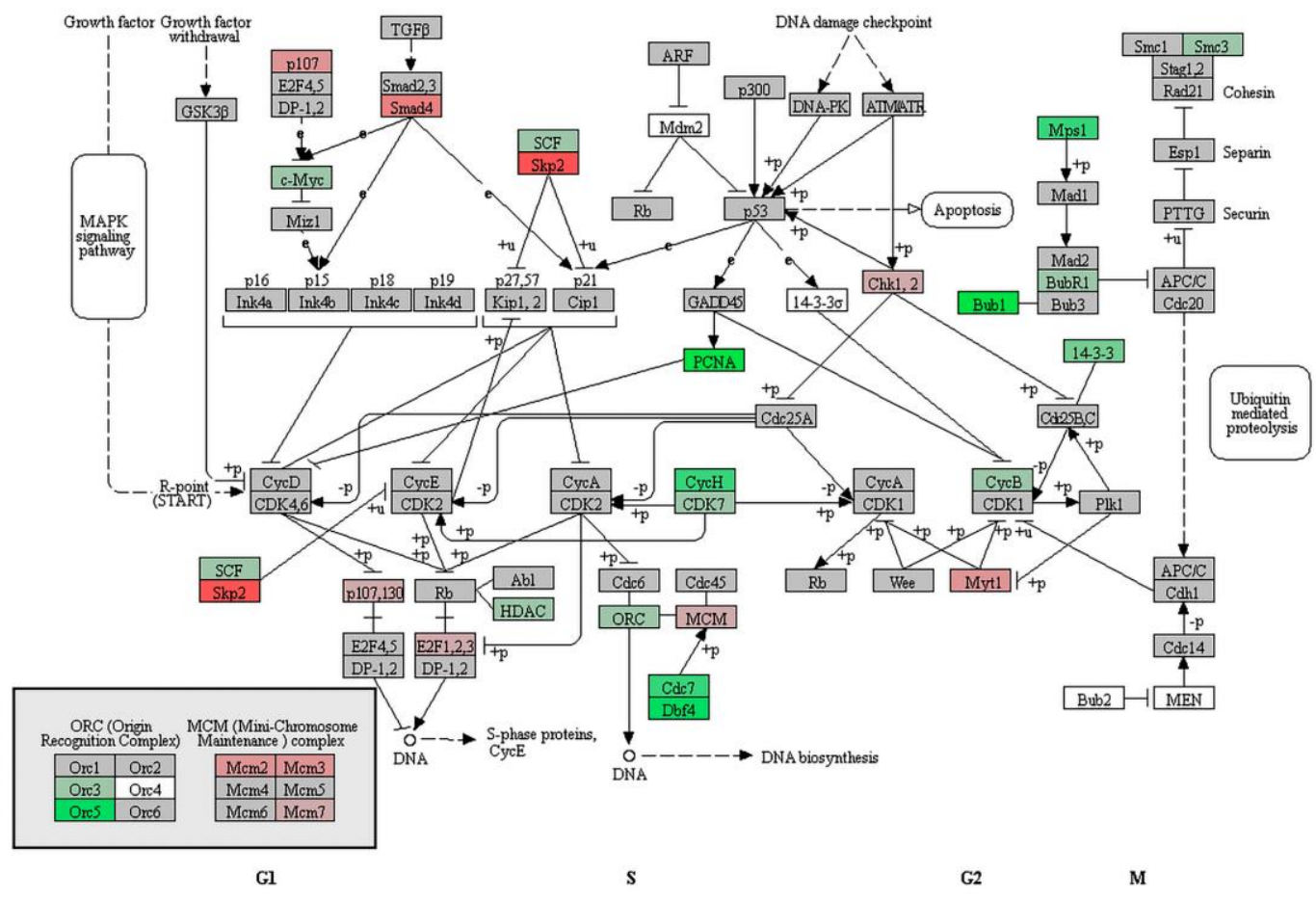

B Abisil $50 \mu \mathrm{g} / \mathrm{ml}$ compared to non-treated cells

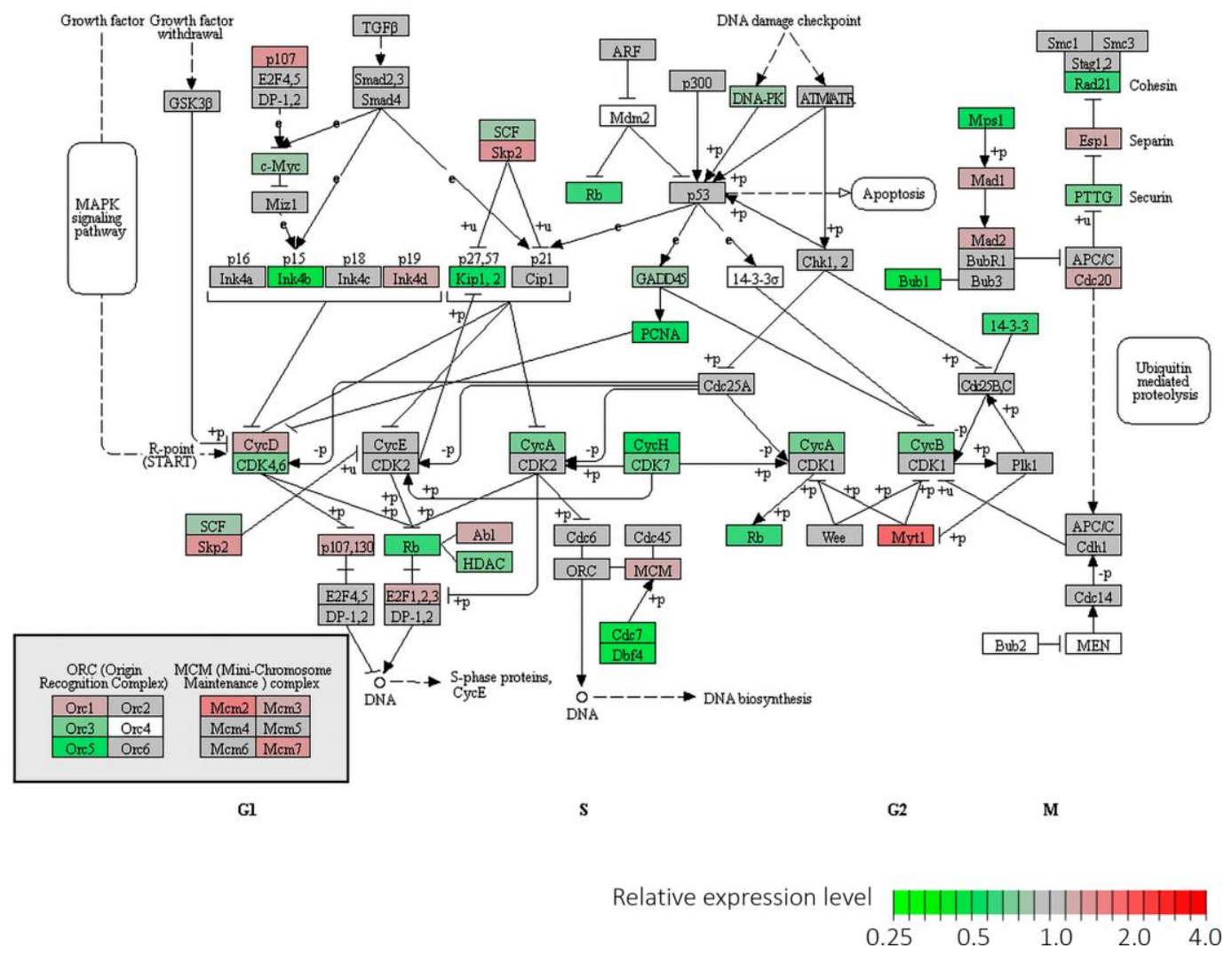

Figure 13. Diagram illustrating expression changes of genes participating cell cycle signaling pathway (KEGG) after Abisil treatment (MRC5-SV40 cell line): $5 \mu \mathrm{g} / \mathrm{ml}$ (A) and $50 \mu \mathrm{g} / \mathrm{ml}$ (B). Green - downregulation, red - upregulation. 
Sometimes hormetins have genotoxic effects, especially at high doses. There are complex transcriptomic markers of genotoxicity, e.g. combination of increased expression levels of ATF3,CDKN1A and GADD45A genes [39]. In the case of Abisil we could not observe any significant increase ( 2 times and more, FDR $<0.05$ ) in activity of these genes neither at low nor at high concentrations of the drug (Supplementary Tables 1,2). At the same time, we noted statistically significant changes (both increase and decrease) in differential expression of genes, involved in the major DNA repair pathways: nucleotide excision repair, mismatch repair and homologous recombination.

Most likely Abisil introduces a shift in cell energy metabolism: whereas overall oxygen consumption rate was intact, the activity of glycolysis was significantly decreased. At the same time, we observed a decrease in

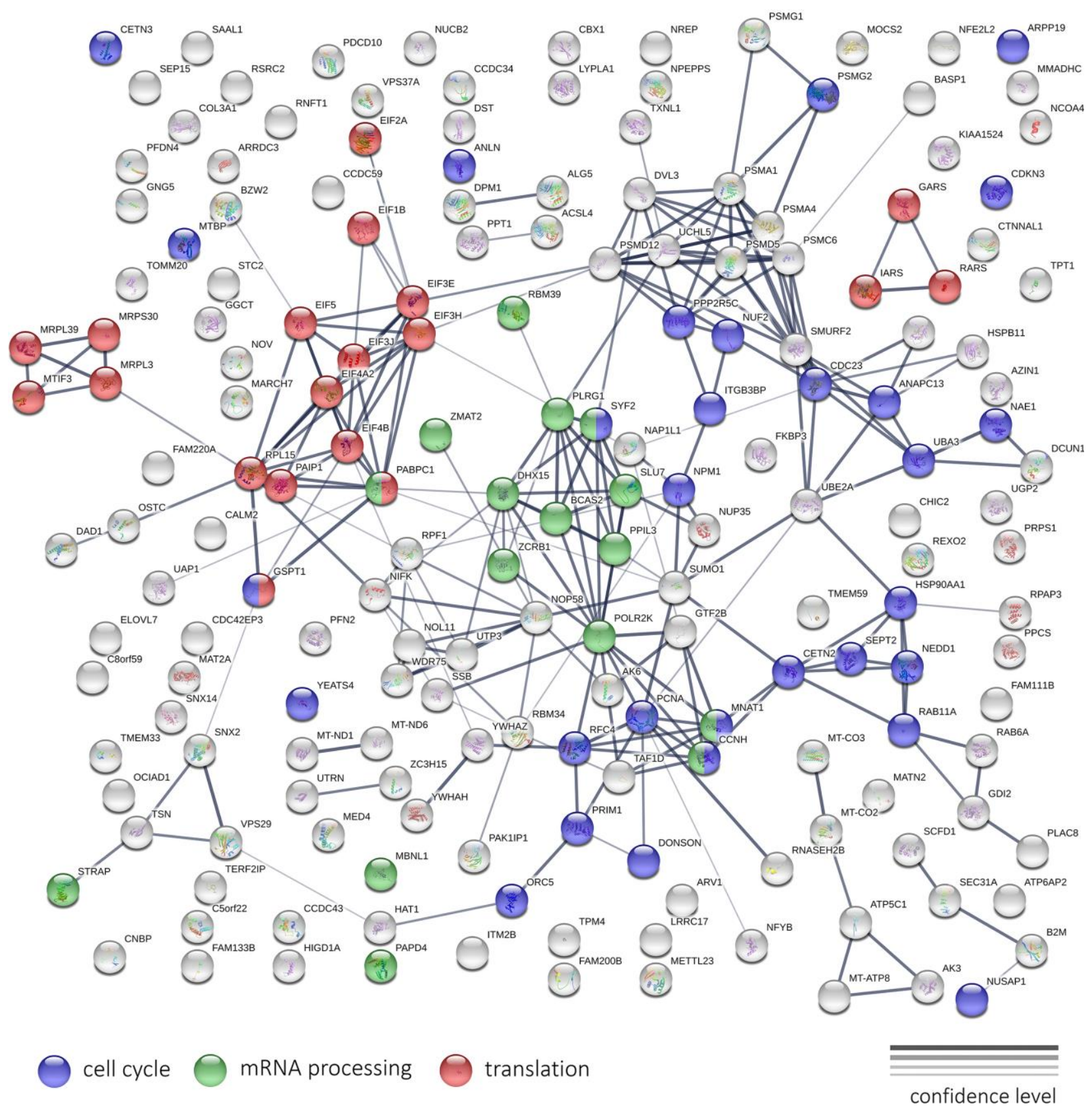

Figure 14. The interaction network of protein products encoded by top 200 genes downregulated after Abisil treatment, according to RNA-Seq data (5 $\mathrm{\mu g} / \mathrm{ml}$; MRC5-SV40 cell line). The width of the connecting lines indicates the confidence level of protein interaction (best - mentions in curated databases, experimental data for human; worst - found interacting putative homologs in other organisms). 
mitochondrial potential, reduce in ROS levels and found a predominant decrease in the expression of genes involved in oxidative phosphorylation (namely those that are encoded in mitochondrial genome). Moreover, the effect of Abisil treatment extends not only to energy metabolism, but also causes a significant transcriptional reprogramming spanning thousands of genes involved in key cell pathways: we noted that about $15-20 \%$ of genes decrease their expression both at the transcriptome and proteome levels.

Treatment of cells with Abisil at a lowest concentration also resulted in bidirectional changes in the expression of ribosomal proteins and stimulation of amino acid biogenesis genes transcription. Impaired ribosome biogenesis is associated with cancer and aging [40]. At the proteome level, Abisil drops the expression of thousands of genes and downregulated proteins involved in the initiation of transcription and translation.

Abisil may contribute to the activation of VEGF pathway (Supplementary Figure 1), which regulates vascular development and blood and lymphatic vessel function [41]. It also activated T- and B-cell pathways, which can potentially delay immunosenescence.

In the present study, we demonstrated that Abisil (in a concentration of $50 \mu \mathrm{g} / \mathrm{ml}$ ) effectively stimulated autophagy and reduced mitochondrial potential but did not decrease the number of mitochondrial DNA. It also induced drop of mitochondrial potential, without induction of mitophagy. Abisil did not cause mitophagy in MRC5-SV40 and LECH-4 cells. At the same time, it decreased the transcription levels of genes encoding subunits of mitochondrial complexes I, III, IV, V and the content of cytochrome c protein. It could be a mechanism for observed antioxidant effect and makes Abisil similar to metformin, that can inhibit complex I in intact cells [42]. In addition, it was recently observed that the mild depolarization of the inner mitochondrial membrane is another cause of the reduction of mitochondrial ROS [43].

As outer membrane of mitochondria is non-specifically permeable to all low-molecular-weight solutes, whereas the inner membrane is impermeable except through specific transporters [44], effects observed in this study could be explained by integration of one of the Abisil components into the outer membrane of mitochondria. That could lead to the decrease of mitochondrial potential without severe changes in oxygen consumption rate. ROS level reduction should be connected partially to increase of NADH oxidoreductases (Supplementary Figure 2) and superoxide dismutase 2. In addition, polyprenols, which are about $1.5 \%$ of Abisil, can act as scavengers of ROS [31].
In our opinion, it may be quite difficult to identify the main mechanism of action of Abisil, revealing its direct targets. There are at least two reasons for this. First, it is a multicomponent substance of natural origin, which is likely to have a complex impact on a cell. Secondly, at the transcriptomic and proteomic levels, we observe not only the primary effect (activation/inhibition of direct targets), but also all downstream events, such as activation of autophagy, cell cycle suppression, and so on. Moreover, downstream events on their scale, apparently, significantly exceed the primary effect, because transcriptomic and proteomic changes caused by Abisil treatment affect thousands of genes.

Regarding other transcriptomic and proteomic changes, Abisil led to a decrease in the expression of genes involved in the cell cycle and related processes. It is consistent with the results of the studies demonstrating that natural terpenoids may induce cell cycle arrest [17, 45]. Moreover, terpenoids are considered as potential chemopreventive and anti-cancer agents for tumor therapy $[45,46]$.

Since Abisil reduced the activity of fatty acid metabolism genes, it is expedient to test its effect on a metabolic syndrome and obesity. At least, switching from glucose metabolism to fatty acid metabolism, for example, with aging, increases the risk of ischemic myocardial damage due to free radicals and damage to DNA: beta-oxidation of fatty acids involves more oxygen than oxidation of pyruvate, and therefore provokes generation of more ROS [47]. PPAR $\delta$ is a fatty acid sensor that enhances mitochondrial oxidation. Abisil significantly activates PPAR $\delta$ expression both at low and high concentrations. Agonists of PPAR $\delta$ affect energy homeostasis, anti-inflammation and insulin sensitivity and present an attractive target in Alzheimer's disease pathogenesis [48].

On a proteome level Abisil treatment resulted in downregulation of mTOR, RICTOR, and Ras-related protein Rab-13. It is known that attenuation of TORC1 signaling delays replicative and oncogenic RAS-induced senescence [49]. Abisil decreases the expression of TGFBR1 receptor, which is evidently involved in tissue fibrosis [50]. Fibrosis is associated with upregulation of RBL1 [51], CDK9 [52], Renin receptor [53], mitogenactivated protein kinase p38a (Mapk14 gene) [54]. TWEAK signals through its receptor, fibroblast growth factor inducible 14 (Fn14; TNFRSF12A) also modulates fibrosis in several organs, including heart, kidney, colon, and muscle [55]. Remarkably, all these target genes are downregulated by Abisil in the cell proteome.

Induction of cytosolic DNA-sensing pathway and innate and adaptive immune response and a bidirectional impact 
on endocytosis by Abisil proposes its antimicrobial and anti-viral activity. Considering the ongoing Covid-19 pandemic, these effects may be useful in prevention and treatment.

In conclusion, in small doses, Abisil exerted an antioxidant and anabolic effects, stimulated vascular growth factors and adaptive immunity genes. The mechanism of its action can include mitohormesis, since it affected autophagy and mitophagy, as well as the respiratory function of mitochondria. Abisil has a potential as anti-fibrotic, anti-metabolic drug and immunomodulatory substance, affecting many targets and cellular pathways.

\section{AUTHOR CONTRIBUTIONS}

A.L., A.M., F.M. and A.K. designed the study. A.L., G.K., P.V., P.M., O.A., Yu.V. A.B., D.G. and N.Z. performed experiments. A.M., A.L. and G.K. wrote the manuscript. All authors analyzed data and contributed to the final version of the manuscript.

\section{ACKNOWLEDGMENTS}

Authors thank Initium-Pharm, LTD for supplying Abisil and EIMB RAS "Genome" center (Moscow, Russia) (http://www.eimb.ru/RUSSIAN_NEW/INSTITUTE/ccu _genome_c.php) for performing transcriptome sequencing and analysis.

\section{CONFLICTS OF INTEREST}

F. Maganova is the founder of pharmacological company Initium-Pharm LLC (Moscow, Russia). Other authors declare no conflicts of interest.

\section{FUNDING}

Antioxidant properties studies (Figures 1-3) and gene expression studies (Figures 12-14) were supported by Initium-Pharm, LTD. Assessment of autophagy and metabolism (Figures 4-11) was supported by Grant 075-15-2019-1660 from the Ministry of Science and Higher Education of the Russian Federation.

\section{REFERENCES}

1. Foreman KJ, Marquez N, Dolgert A, Fukutaki K, Fullman N, McGaughey M, Pletcher MA, Smith AE, Tang K, Yuan CW, Brown JC, Friedman J, He J, et al. Forecasting life expectancy, years of life lost, and allcause and cause-specific mortality for 250 causes of death: reference and alternative scenarios for 201640 for 195 countries and territories. Lancet. 2018; 392:2052-90.
https://doi.org/10.1016/S0140-6736(18)31694-5 PMID:30340847

2. Ismail K, Nussbaum L, Sebastiani P, Andersen S, Perls T, Barzilai N, Milman S. Compression of Morbidity Is Observed Across Cohorts with Exceptional Longevity. J Am Geriatr Soc. 2016; 64:1583-91. https://doi.org/10.1111/jgs.14222 PMID:27377170

3. Lewis KN, Mele J, Hornsby PJ, Buffenstein R. Stress resistance in the naked mole-rat: the bare essentials - a mini-review. Gerontology. 2012; 58:453-62. https://doi.org/10.1159/000335966 PMID:22572398

4. Kennedy BK, Berger SL, Brunet A, Campisi J, Cuervo AM, Epel ES, Franceschi C, Lithgow GJ, Morimoto RI, Pessin JE, Rando TA, Richardson A, Schadt EE, et al. Geroscience: linking aging to chronic disease. Cell. 2014; 159:709-13.

https://doi.org/10.1016/j.cell.2014.10.039 PMID:25417146

5. Chattopadhyay D, Thirumurugan K. Longevity promoting efficacies of different plant extracts in lower model organisms. Mech Ageing Dev. 2018; 171:47-57. https://doi.org/10.1016/i.mad.2018.03.002 PMID:29526449

6. Kudryavtseva AV, Lipatova AV, Zaretsky AR, Moskalev AA, Fedorova MS, Rasskazova AS, Shibukhova GA, Snezhkina AV, Kaprin AD, Alekseev BY, Dmitriev AA, Krasnov GS. Important molecular genetic markers of colorectal cancer. Oncotarget. 2016; 7:53959-83.

https://doi.org/10.18632/oncotarget.9796 PMID:27276710

7. Moldogazieva NT, Mokhosoev IM, Mel'nikova TI, Porozov YB, Terentiev AA. Oxidative Stress and Advanced Lipoxidation and Glycation End Products (ALEs and AGEs) in Aging and Age-Related Diseases. Oxid Med Cell Longev. 2019; 2019:3085756. https://doi.org/10.1155/2019/3085756 PMID:31485289

8. Harman D. Aging: a theory based on free radical and radiation chemistry. J Gerontol. 1956; 11:298-300.

https://doi.org/10.1093/geroni/11.3.298 PMID:13332224

9. Milisav I, Ribarič S, Poljsak B. Antioxidant Vitamins and Ageing. Subcell Biochem. 2018; 90:1-23. https://doi.org/10.1007/978-981-13-2835-0 1 PMID:30779004

10. Cox CS, McKay SE, Holmbeck MA, Christian BE, Scortea AC, Tsay AJ, Newman LE, Shadel GS. Mitohormesis in Mice via Sustained Basal Activation of Mitochondrial and Antioxidant Signaling. Cell Metab. 2018; 28:77686.e5.

https://doi.org/10.1016/j.cmet.2018.07.011 PMID: $\underline{0122556}$ 
11. Bareja A, Lee DE, White JP. Maximizing Longevity and Healthspan: Multiple Approaches All Converging on Autophagy. Front Cell Dev Biol. 2019; 7:183.

https://doi.org/10.3389/fcell.2019.00183 PMID:31555646

12. Bazopoulou $D$, Knoefler $D$, Zheng $Y$, Ulrich $K$, Oleson $B J$, Xie L, Kim M, Kaufmann A, Lee YT, Dou Y, Chen Y, Quan $S$, Jakob U. Developmental ROS individualizes organismal stress resistance and lifespan. Nature. 2019; 576:301-05.

https://doi.org/10.1038/s41586-019-1814-y

PMID:31801997

13. Korolchuk VI, Miwa S, Carroll B, von Zglinicki T. Mitochondria in Cell Senescence: Is Mitophagy the Weakest Link? EBioMedicine. 2017; 21:7-13. https://doi.org/10.1016/j.ebiom.2017.03.020 PMID:28330601

14. Fang EF, Scheibye-Knudsen $M$, Brace LE, Kassahun $H$, SenGupta T, Nilsen $H$, Mitchell JR, Croteau DL, Bohr VA. Defective mitophagy in XPA via PARP-1 hyperactivation and $\mathrm{NAD}(+) / \mathrm{SIRT} 1$ reduction. Cell. 2014; 157:882-96.

https://doi.org/10.1016/i.cell.2014.03.026

PMID:24813611

15. Rubinsztein DC, Mariño G, Kroemer G. Autophagy and aging. Cell. 2011; 146:682-95.

https://doi.org/10.1016/i.cell.2011.07.030

PMID:21884931

16. Kudryavtseva A, Krasnov G, Lipatova A, Alekseev B, Maganova F, Shaposhnikov M, Fedorova M, Snezhkina A, Moskalev A. Effects of Abies sibirica terpenes on cancer- and aging-associated pathways in human cells. Oncotarget. 2016; 7:83744-54.

https://doi.org/10.18632/oncotarget.13467 PMID:27888805

17. Nevzorova YA, Grossmann J, Trautwein C. Antitumorigenic and anti-angiogenic effects of natural conifer Abies sibirica terpenoids in vivo and in vitro. Biomed Pharmacother. 2017; 89:386-95.

https://doi.org/10.1016/j.biopha.2017.02.035

PMID:28254663

18. Bolger AM, Lohse M, Usadel B. Trimmomatic: a flexible trimmer for Illumina sequence data. Bioinformatics. 2014; 30:2114-20.

https://doi.org/10.1093/bioinformatics/btu170 PMID:24695404

19. Dobin A, Davis CA, Schlesinger F, Drenkow J, Zaleski C, Jha S, Batut P, Chaisson M, Gingeras TR. STAR: ultrafast universal RNA-seq aligner. Bioinformatics. 2013; 29:15-21.

https://doi.org/10.1093/bioinformatics/bts635

PMID:23104886
20. Wang L, Wang S, Li W. RSeQC: quality control of RNAseq experiments. Bioinformatics. 2012; 28:2184-85. https://doi.org/10.1093/bioinformatics/bts356 PMID:22743226

21. Liao Y, Smyth GK, Shi W. featureCounts: an efficient general purpose program for assigning sequence reads to genomic features. Bioinformatics. 2014; 30:923-30. https://doi.org/10.1093/bioinformatics/btt656 PMID:24227677

22. Bereman MS, Egertson JD, MacCoss MJ. Comparison between procedures using SDS for shotgun proteomic analyses of complex samples. Proteomics. 2011; 11:2931-35.

https://doi.org/10.1002/pmic.201100045 PMID:21656683

23. Smith PK, Krohn RI, Hermanson GT, Mallia AK, Gartner FH, Provenzano MD, Fujimoto EK, Goeke NM, Olson BJ, Klenk DC. Measurement of protein using bicinchoninic acid. Anal Biochem. 1985; 150:76-85. https://doi.org/10.1016/0003-2697(85)90442-7 PMID:3843705

24. Bairoch A, Apweiler R. The SWISS-PROT protein sequence database and its supplement TrEMBL in 2000. Nucleic Acids Res. 2000; 28:45-48. https://doi.org/10.1093/nar/28.1.45 PMID:10592178

25. Tyanova S, Temu T, Cox J. The MaxQuant computational platform for mass spectrometry-based shotgun proteomics. Nat Protoc. 2016; 11:2301-19.

https://doi.org/10.1038/nprot.2016.136 PMID:27809316

26. Szklarczyk D, Franceschini A, Wyder $S$, Forslund $K$, Heller D, Huerta-Cepas J, Simonovic M, Roth A, Santos A, Tsafou KP, Kuhn M, Bork P, Jensen LJ, von Mering C. STRING v10: protein-protein interaction networks, integrated over the tree of life. Nucleic Acids Res. 2015; 43:D447-52. https://doi.org/10.1093/nar/gku1003 PMID:25352553

27. Supek $F$, Bošnjak $M$, Škunca $N$, Šmuc $T$. REVIGO summarizes and visualizes long lists of gene ontology terms. PLoS One. 2011; 6:e21800.

https://doi.org/10.1371/journal.pone.0021800 PMID:21789182

28. Skulachev VP. Mitochondrial filaments and clusters as intracellular power-transmitting cables. Trends Biochem Sci. 2001; 26:23-29.

https://doi.org/10.1016/s0968-0004(00)01735-7 PMID:11165513

29. Priault M, Salin B, Schaeffer J, Vallette FM, di Rago JP, Martinou JC. Impairing the bioenergetic status and the biogenesis of mitochondria triggers mitophagy in yeast. Cell Death Differ. 2005; 12:1613-21. 
https://doi.org/10.1038/sj.cdd.4401697

PMID:15947785

30. Elmore SP, Qian T, Grissom SF, Lemasters JJ. The mitochondrial permeability transition initiates autophagy in rat hepatocytes. FASEB J. 2001; 15:2286-87.

https://doi.org/10.1096/fj.01-0206fje

PMID:11511528

31. Proshkina E, Plyusnin S, Babak T, Lashmanova E, Maganova F, Koval L, Platonova E, Shaposhnikov M, Moskalev A. Terpenoids as Potential Geroprotectors. Antioxidants (Basel). 2020; 9:529. https://doi.org/10.3390/antiox9060529 PMID:32560451

32. Ayaz M, Sadiq A, Junaid M, Ullah F, Subhan F, Ahmed J. Neuroprotective and Anti-Aging Potentials of Essential Oils from Aromatic and Medicinal Plants. Front Aging Neurosci. 2017; 9:168.

https://doi.org/10.3389/fnagi.2017.00168

PMID:28611658

33. Chenysheva GA, Smol'akova VA, Kutchin AV, Chukicheva IY, Plotnikov MB. Neuroprotective Effects of Dibornol in Focal Cerebral Ischemia/Reperfusion in Rats. Bull Exp Biol Med. 2018; 166:15-18.

https://doi.org/10.1007/s10517-018-4278-4 PMID:30417302

34. Hordyjewska A, Ostapiuk A, Horecka A, Kurzepa J. Betulin and betulinic acid: triterpenoids derivatives with a powerful biological potential. Phytochemistry Reviews. 2019; 18:929-51. https://doi.org/10.1007/s11101-019-09623-1

35. Cao S, Tian XL, Yu WX, Zhou LP, Dong XL, Favus MJ, Wong MS. Oleanolic Acid and Ursolic Acid Improve Bone Properties and Calcium Balance and Modulate Vitamin D Metabolism in Aged Female Rats. Front Pharmacol. 2018; 9:1435.

https://doi.org/10.3389/fphar.2018.01435

PMID:30564129

36. Palmeira CM, Teodoro JS, Amorim JA, Steegborn C, Sinclair DA, Rolo AP. Mitohormesis and metabolic health: The interplay between ROS, cAMP and sirtuins. Free Radic Biol Med. 2019; 141:483-91. https://doi.org/10.1016/j.freeradbiomed.2019.07.017 PMID:31349039

37. Tang S, Liang J, Xiang C, Xiao Y, Wang X, Wu J, Li G, Cheke RA. A general model of hormesis in biological systems and its application to pest management. J R Soc Interface. 2019; 16:20190468.

https://doi.org/10.1098/rsif.2019.0468

PMID:31431187

38. Berry R 3rd, López-Martínez G. A dose of experimental hormesis: When mild stress protects and improves animal performance. Comp Biochem Physiol A Mol Integr Physiol. 2020; 242:110658.

https://doi.org/10.1016/j.cbpa.2020.110658

PMID:31954863

39. Li HH, Chen R, Hyduke DR, Williams A, Frötschl R, Ellinger-Ziegelbauer $\mathrm{H}, \mathrm{O}$ 'Lone $\mathrm{R}$, Yauk $\mathrm{CL}$, Aubrecht $\mathrm{J}$, Fornace AJ Jr. Development and validation of a highthroughput transcriptomic biomarker to address 21st century genetic toxicology needs. Proc Natl Acad Sci USA. 2017; 114:E10881-89.

https://doi.org/10.1073/pnas.1714109114 PMID:29203651

40. Turi Z, Lacey M, Mistrik M, Moudry P. Impaired ribosome biogenesis: mechanisms and relevance to cancer and aging. Aging (Albany NY). 2019; 11:2512-40.

https://doi.org/10.18632/aging.101922 PMID:31026227

41. Koch S, Claesson-Welsh L. Signal transduction by vascular endothelial growth factor receptors. Cold Spring Harb Perspect Med. 2012; 2:a006502.

https://doi.org/10.1101/cshperspect.a006502 PMID:22762016

42. Fontaine E. Metformin-Induced Mitochondrial Complex I Inhibition: Facts, Uncertainties, and Consequences. Front Endocrinol (Lausanne). 2018; 9:753.

https://doi.org/10.3389/fendo.2018.00753 PMID:30619086

43. Vyssokikh MY, Holtze S, Averina OA, Lyamzaev KG, Panteleeva AA, Marey MV, Zinovkin RA, Severin FF, Skulachev MV, Fasel N, Hildebrandt TB, Skulachev VP. Mild depolarization of the inner mitochondrial membrane is a crucial component of an anti-aging program. Proc Natl Acad Sci USA. 2020; 117:6491-501. https://doi.org/10.1073/pnas.1916414117 PMID:32152094

44. Lemasters JJ. Modulation of mitochondrial membrane permeability in pathogenesis, autophagy and control of metabolism. J Gastroenterol Hepatol. 2007 (Suppl 1); 22:S31-37.

https://doi.org/10.1111/i.1440-1746.2006.04643.x PMID:17567461

45. Kuttan G, Pratheeshkumar P, Manu KA, Kuttan R. Inhibition of tumor progression by naturally occurring terpenoids. Pharm Biol. 2011; 49:995-1007. https://doi.org/10.3109/13880209.2011.559476 PMID:21936626

46. Thoppil RJ, Bishayee A. Terpenoids as potential chemopreventive and therapeutic agents in liver cancer. World J Hepatol. 2011; 3:228-49.

https://doi.org/10.4254/wjh.v3.i9.228 PMID:21969877 
47. Cao $T$, Liccardo $D$, LaCanna R, Zhang $X$, Lu R, Finck BN, Leigh $T$, Chen $X$, Drosatos K, Tian Y. Fatty Acid Oxidation Promotes Cardiomyocyte Proliferation Rate but Does Not Change Cardiomyocyte Number in Infant Mice. Front Cell Dev Biol. 2019; 7:42.

https://doi.org/10.3389/fcell.2019.00042

PMID:30968022

48. Chamberlain S, Gabriel H, Strittmatter W, Didsbury J. An Exploratory Phase lla Study of the PPAR delta/gamma Agonist T3D-959 Assessing Metabolic and Cognitive Function in Subjects with Mild to Moderate Alzheimer's Disease. J Alzheimers Dis. 2020; 73:1085-103.

https://doi.org/10.3233/JAD-190864

PMID:31884472

49. Kolesnichenko M, Hong L, Liao R, Vogt PK, Sun P. Attenuation of TORC1 signaling delays replicative and oncogenic RAS-induced senescence. Cell Cycle. 2012; 11:2391-401.

https://doi.org/10.4161/cc.20683

PMID:22627671

50. Hillege MM, Galli Caro RA, Offringa $C$, de Wit GM, Jaspers RT, Hoogaars WM. TGF- $\beta$ Regulates Collagen Type I Expression in Myoblasts and Myotubes via Transient Ctgf and Fgf-2 Expression. Cells. 2020; 9:375. https://doi.org/10.3390/cells9020375 PMID:32041253

51. Cazanave S, Podtelezhnikov A, Jensen K, Seneshaw M, Kumar DP, Min HK, Santhekadur PK, Banini B, Mauro AG, Oseini AM, Vincent R, Tanis KQ, Webber AL, et al. The Transcriptomic Signature Of Disease Development
And Progression Of Nonalcoholic Fatty Liver Disease. Sci Rep. 2017; 7:17193.

https://doi.org/10.1038/s41598-017-17370-6

PMID:29222421

52. Qu X, Jiang $M$, Sun $Y B$, Jiang $X$, Fu $P$, Ren $Y$, Wang $D$, Dai L, Caruana G, Bertram JF, Nikolic-Paterson DJ, Li J. The Smad3/Smad4/CDK9 complex promotes renal fibrosis in mice with unilateral ureteral obstruction. Kidney Int. 2015; 88:1323-35. https://doi.org/10.1038/ki.2015.235 PMID:26221756

53. Montes E, Ruiz V, Checa M, Maldonado V, MelendezZajgla J, Montaño M, Ordoñez-Razo R, Cisneros J, García-de-Alba C, Pardo A, Selman M. Renin is an angiotensin-independent profibrotic mediator: role in pulmonary fibrosis. Eur Respir J. 2012; 39:141-48.

https://doi.org/10.1183/09031936.00130310 PMID:21659414

54. Molkentin JD, Bugg D, Ghearing N, Dorn LE, Kim P, Sargent MA, Gunaje J, Otsu K, Davis J. FibroblastSpecific Genetic Manipulation of p38 MitogenActivated Protein Kinase In Vivo Reveals Its Central Regulatory Role in Fibrosis. Circulation. 2017; 136:549-61.

https://doi.org/10.1161/CIRCULATIONAHA.116.026238 PMID:28356446

55. Burkly LC. TWEAK/Fn14 axis: the current paradigm of tissue injury-inducible function in the midst of complexities. Semin Immunol. 2014; 26:229-36. https://doi.org/10.1016/i.smim.2014.02.006 PMID:24636536 


\section{SUPPLEMENTARY MATERIALS}

\section{Supplementary Figures}

A

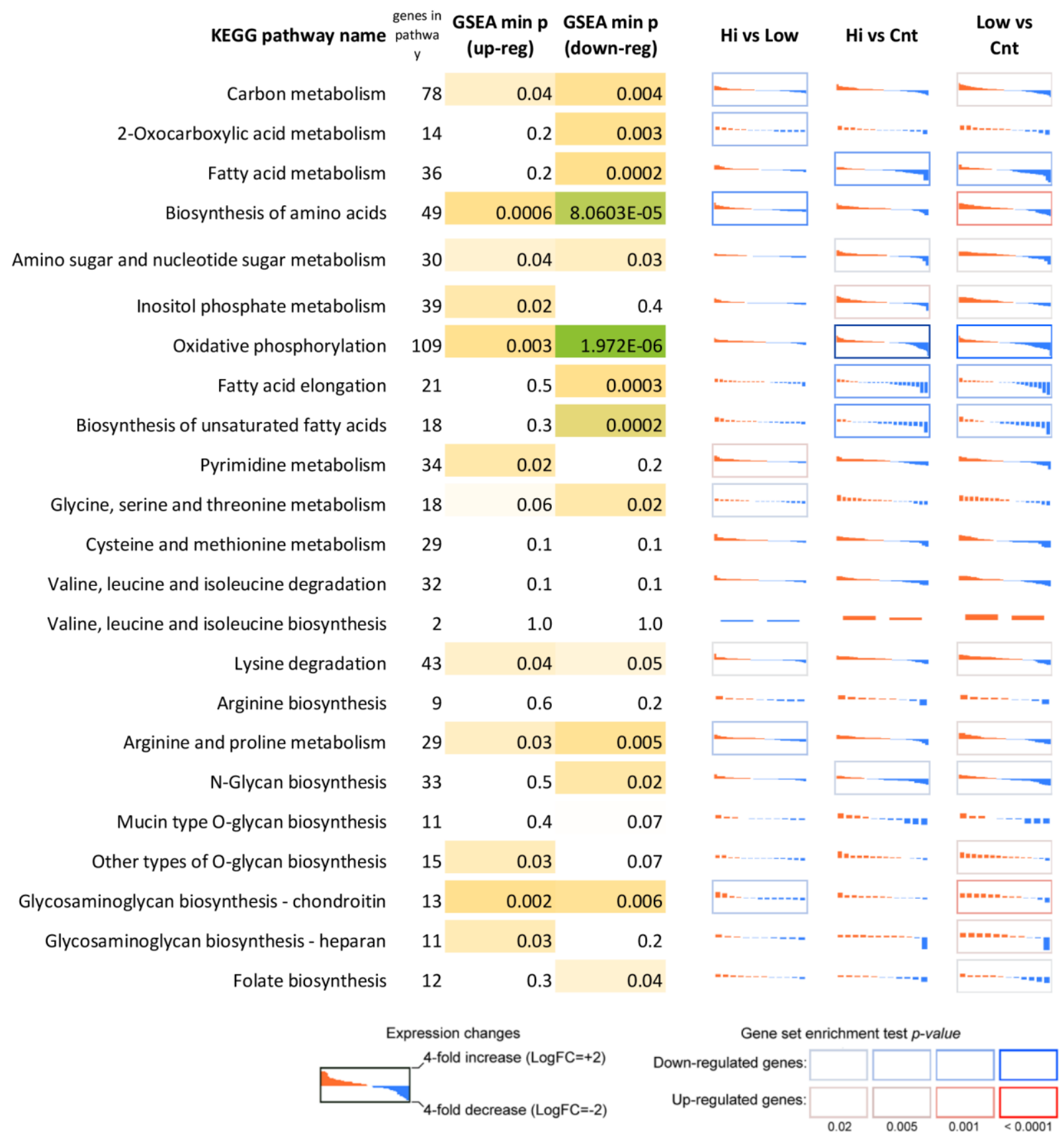


B

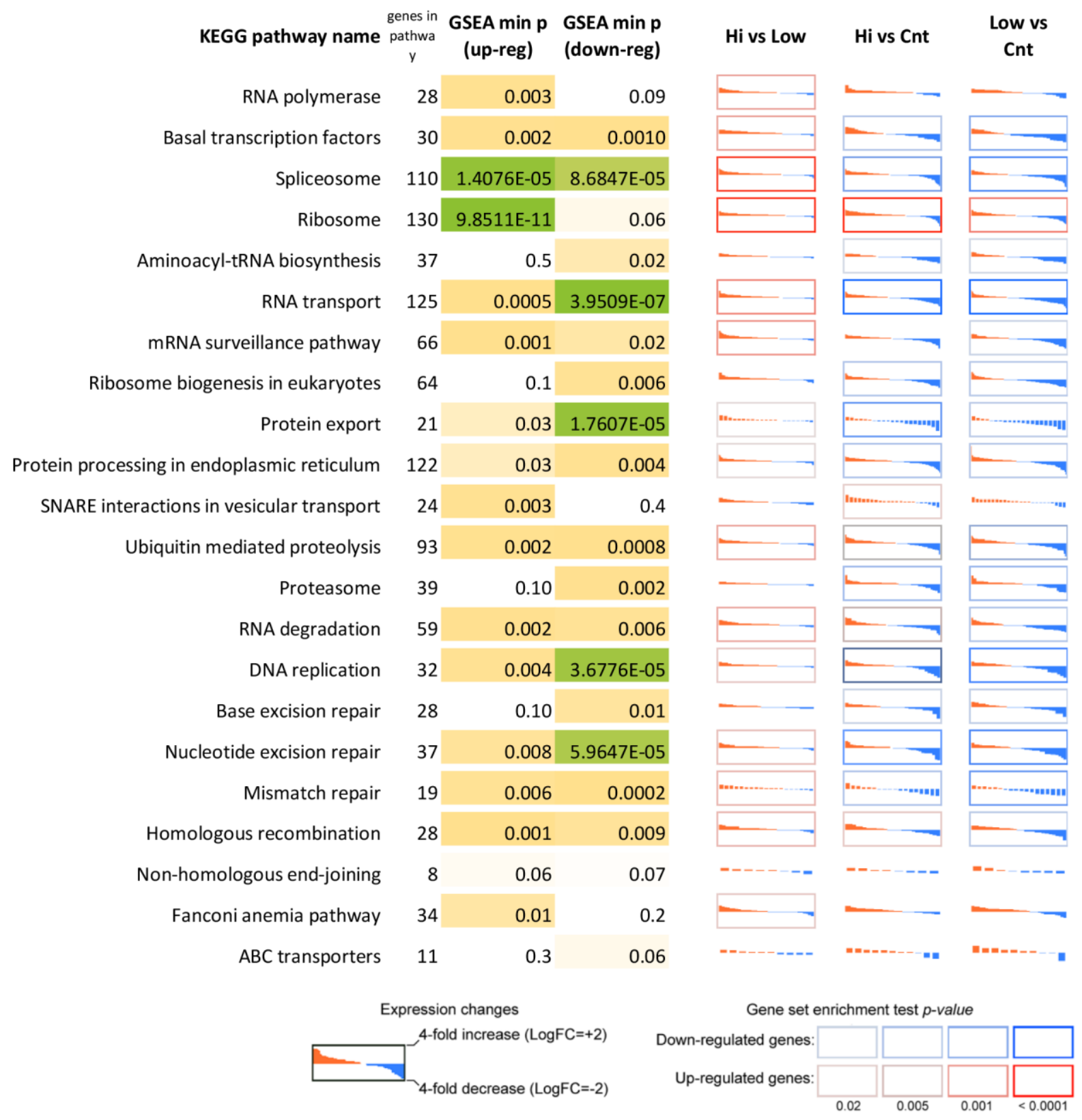




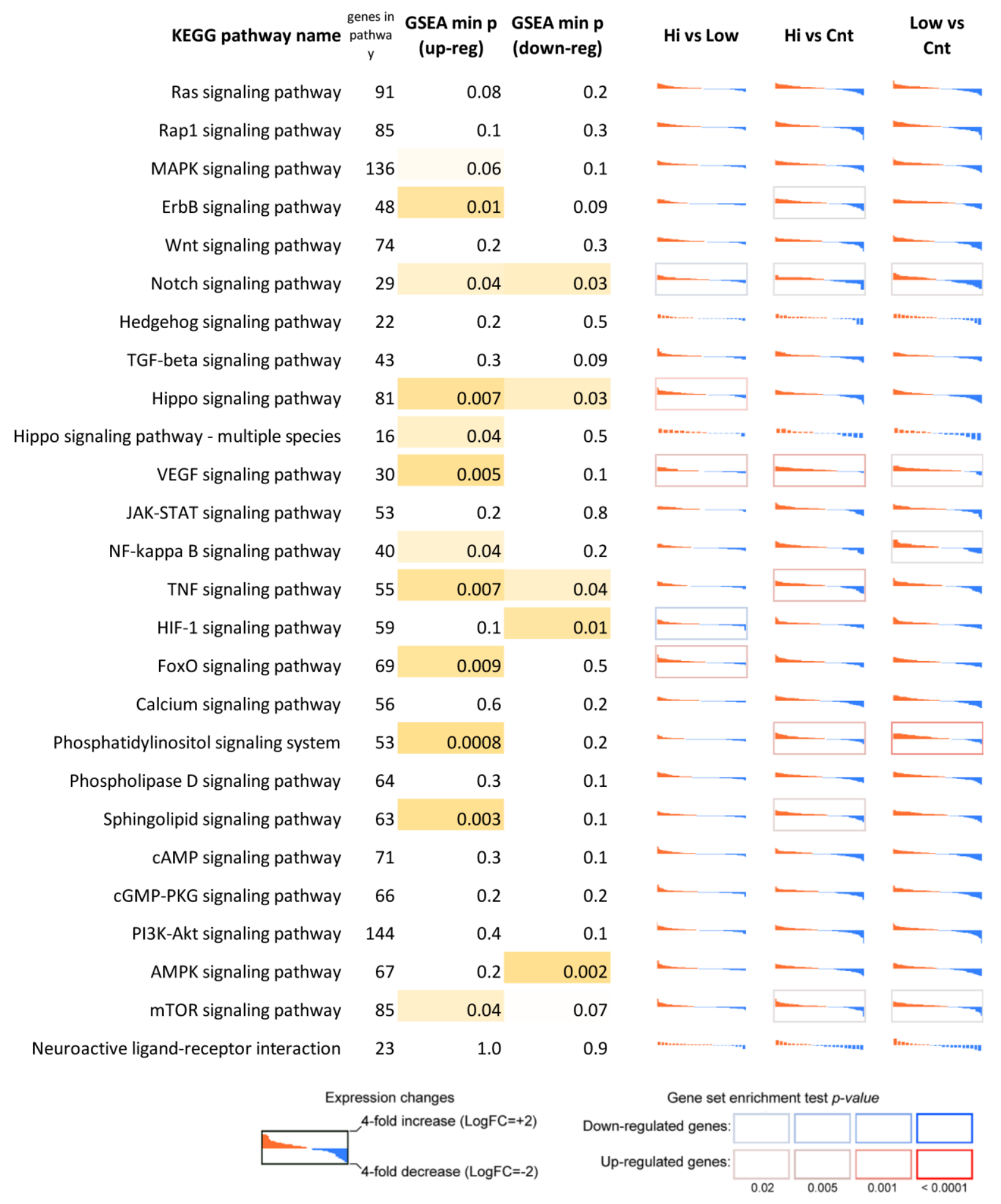


D

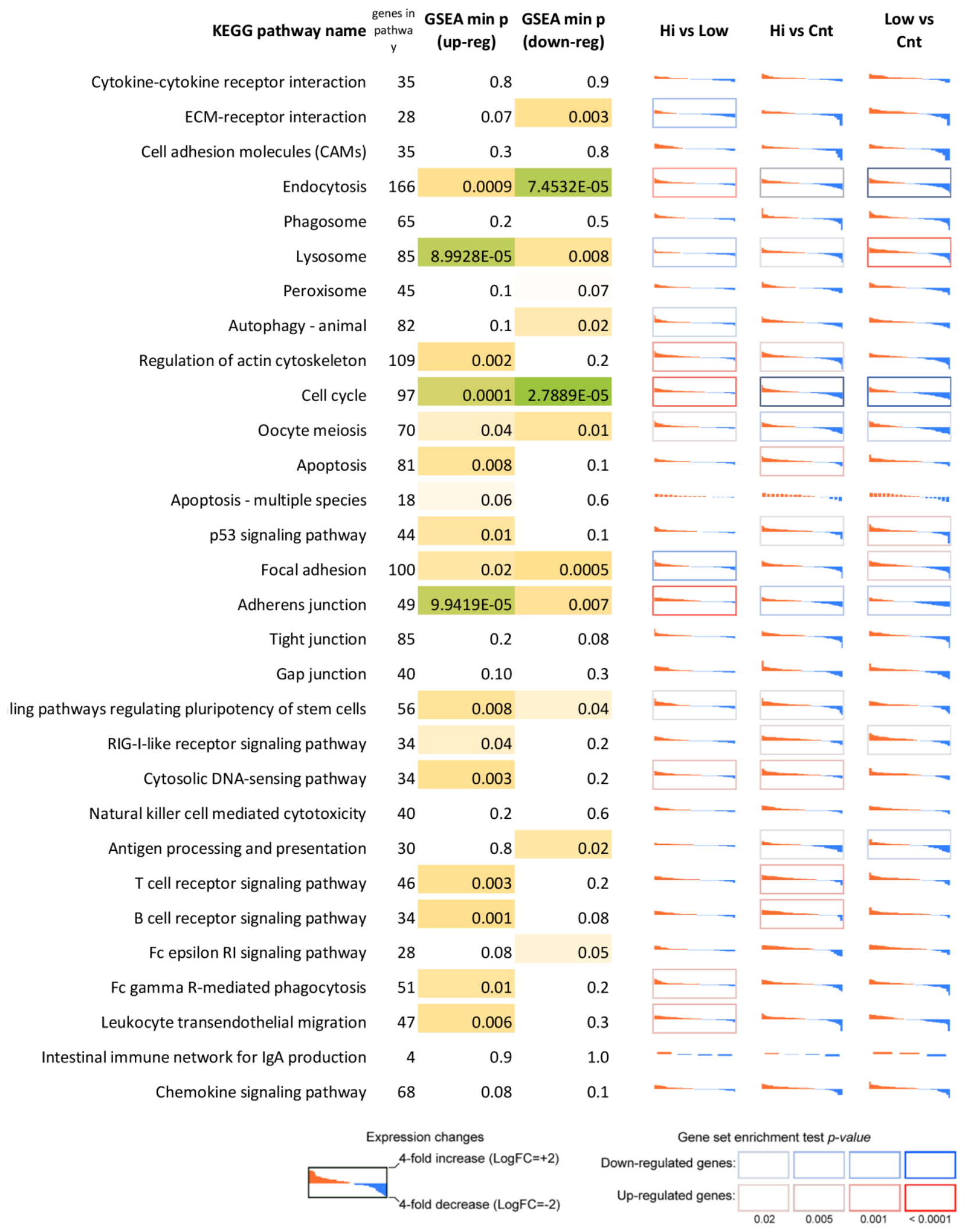




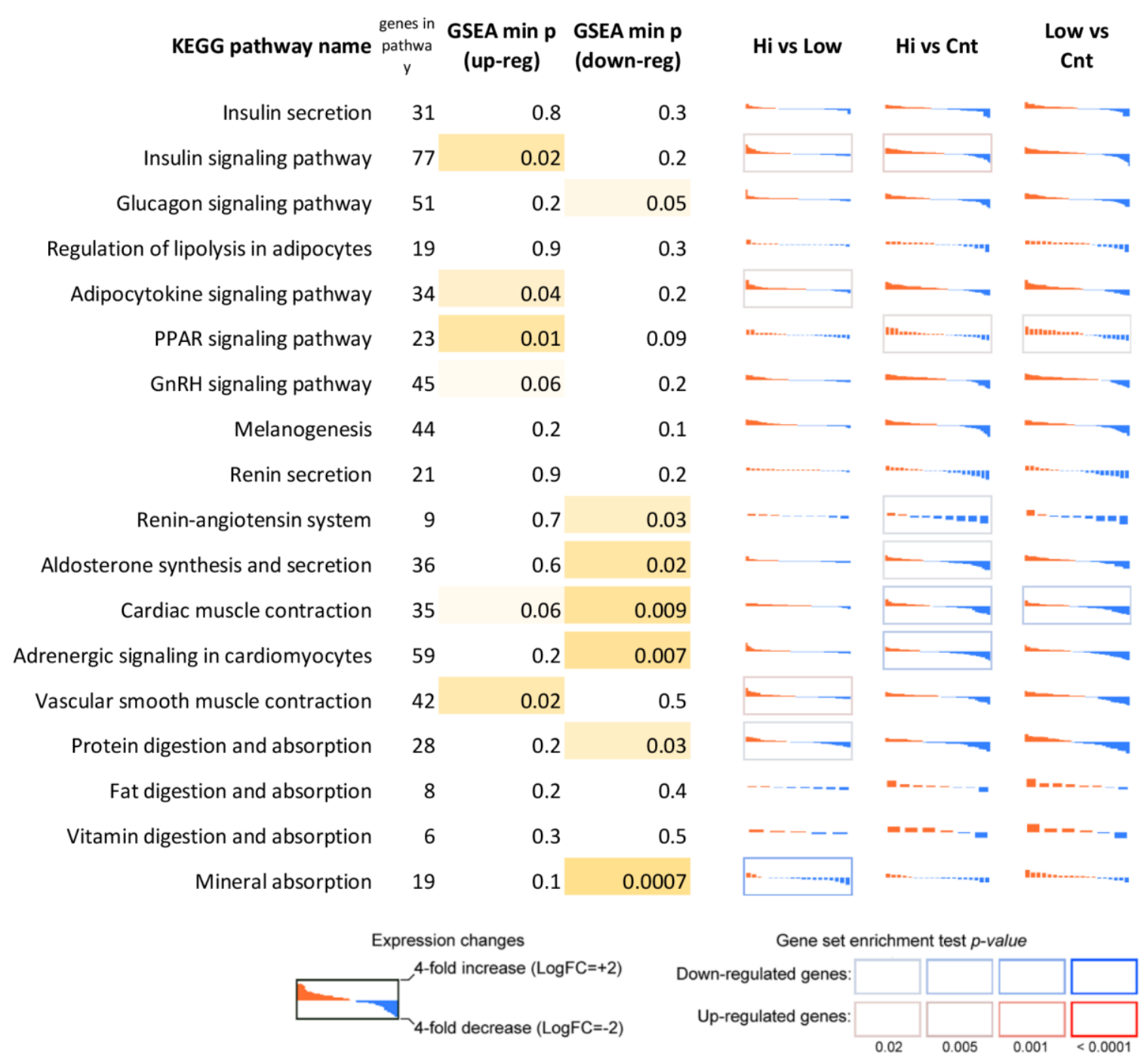

Supplementary Figure 1. Differential expression profiles of genes participating KEGG pathways according to the RNA-Seq data for MRC5-SV40 cell line treated with Abisil. On the figure, each cell demonstrates the sorted expression level log fold changes after Abisil treatment (red - upregulation, blue - downregulation) for genes participating a current KEGG pathway (vertical axis range is from 4-fold downregulation to 4-fold upregulation). Cell borders indicate whether a pathway is enriched with up- (red border) or downregulated (blue border) genes. GSEA min $p$ (up/down-reg) - minimal p-value in a gene set enrichment analyses (GSEA; Fisher's exact test) for the pathway. Hi vs Low - comparison of cells treated with 50 and $5 \mu \mathrm{g} / \mathrm{ml}$; Hi vs Cnt - comparison of cells treated with Abisil $50 \mu \mathrm{g} / \mathrm{ml}$ and nontreated cells; Low vs Cnt - comparison of cells treated with Abisil $5 \mu \mathrm{g} / \mathrm{ml}$ and non-treated cells. (A) Cell metabolism. (B) Main cellular processes. (C) Cell signaling pathways. (D) Immune response pathways, cell cycle, apoptosis, autophagy. (E) Miscellaneous pathways. 
A Abisil $5 \mu \mathrm{g} / \mathrm{ml}$ compared to non-treated cells

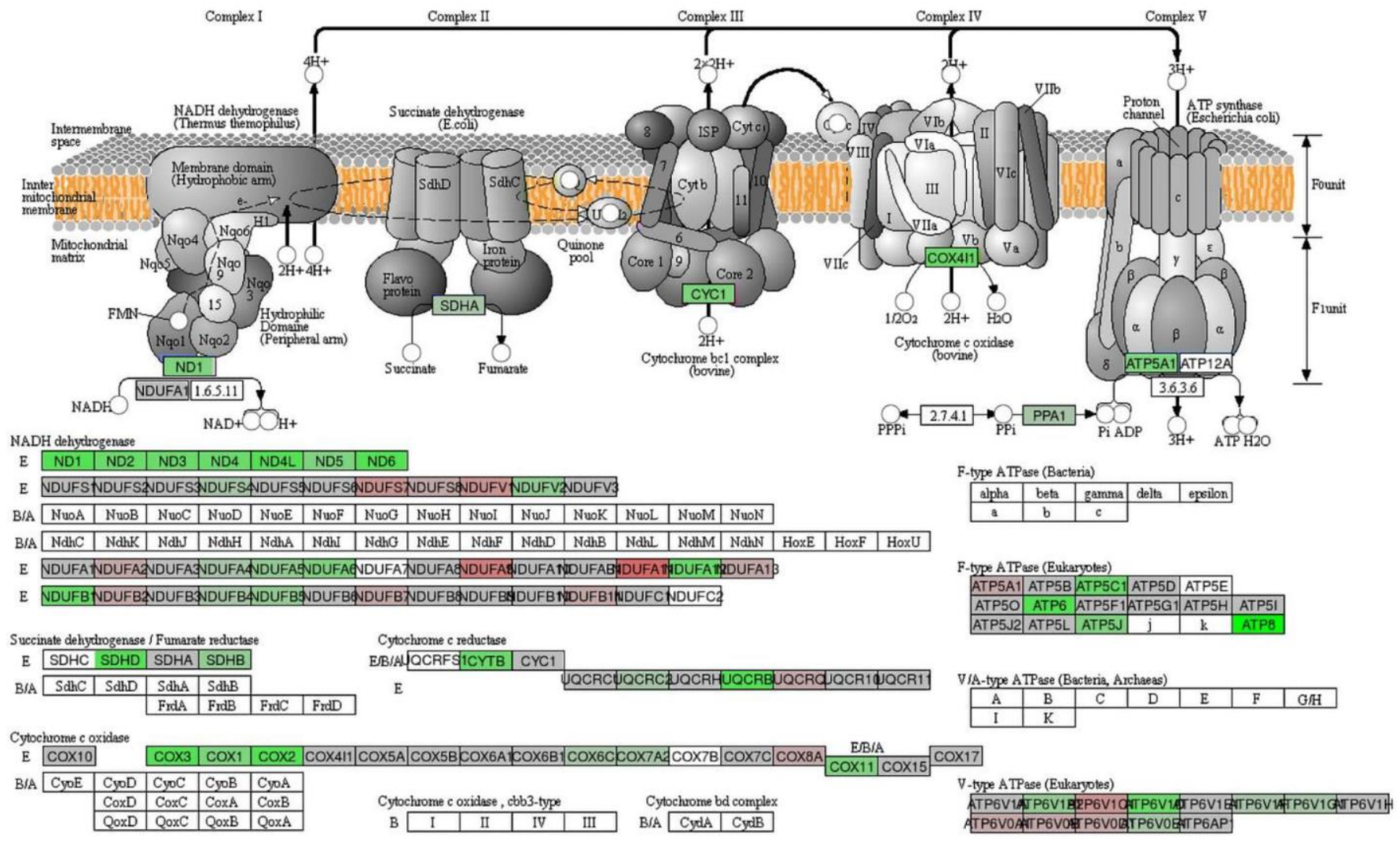

B Abisil $50 \mu \mathrm{g} / \mathrm{ml}$ compared to non-treated cells

NADH dehydrogenase

$$
\frac{\sqrt{\text { ND1 }}}{\frac{\text { NDUFA } 1.65 .11}{\text { NAD+COH+ }}}
$$

\begin{tabular}{|l|l|l|l|l|l|l|}
\hline ND1 & ND2 & ND3 & ND4 & ND4L & ND5 & ND6 \\
\hline
\end{tabular}

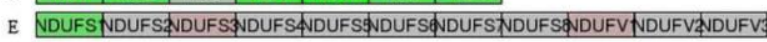

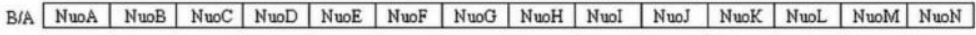

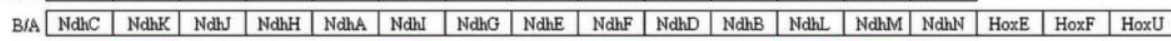

E NDUFA NDUFAZVDUFAZNDUFA

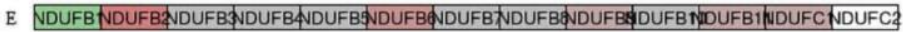

Succinate dehydrogenase /Fumarate reductase Cytochrome c reductase

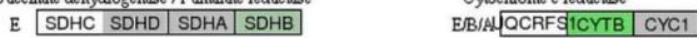

\begin{tabular}{l|l|l|l|l|l|}
\hline BdA & SdhC & SdhD & SdhA & SdhB & \multicolumn{3}{|c|}{} \\
\hline & FrdA & FrdB & FrdC & FrdD \\
\cline { 2 - 3 }
\end{tabular}

E UOCRCWOCRCWOCRHUOCREUOCRAJOCR1фOCR1
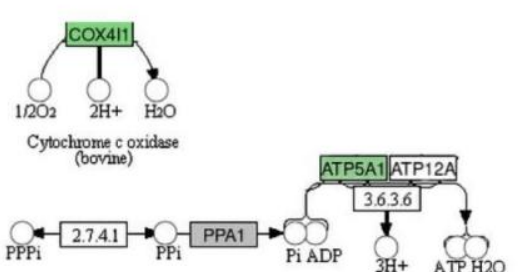

F-type ATPase (Bacteria)

\begin{tabular}{|l|c|c|c|c|}
\hline alpha & beta & gamma & delta & epeilon \\
\hline
\end{tabular}

F-type ATPase (Eukaryotes)

ATP5A1 ATP5B ATP5C1 1 ATP5D ATP5E

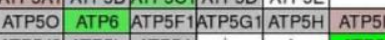

\begin{tabular}{l|l|l|l|l|l|l} 
ATP5J2 & ATP5L & ATP5J & $\mathbf{k}$ & ATP8 & \\
\hline
\end{tabular}

V/A-type ATPase (Bacteria, Archaeas)

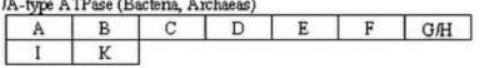

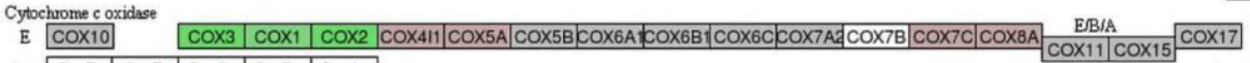

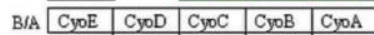
\begin{tabular}{|l|l|l|l|}
\hline CoxD & CoxC & CoxA & CoxB \\
\hline QoxD & QoxC & QoxB & QoxA \\
\hline
\end{tabular}

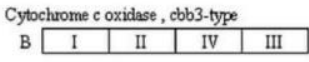

Cytochrome bd complex

B/A CydA CydB

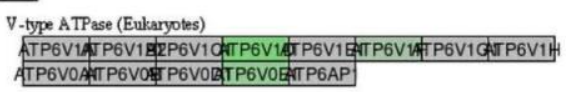

Relative expression level

$\begin{array}{lllll}0.25 & 0.5 & 1.0 & 2.0 & 4.0\end{array}$

Supplementary Figure 2. Diagram illustrating expression changes of genes participating oxidative phosphorylation pathway (KEGG) introduced by Abisil treatment (MRC5-SV40 cell line): $5 \mu \mathrm{g} / \mathrm{ml}$ (A) and $50 \mu \mathrm{g} / \mathrm{ml}$ (B). Green - downregulation, red - upregulation. 


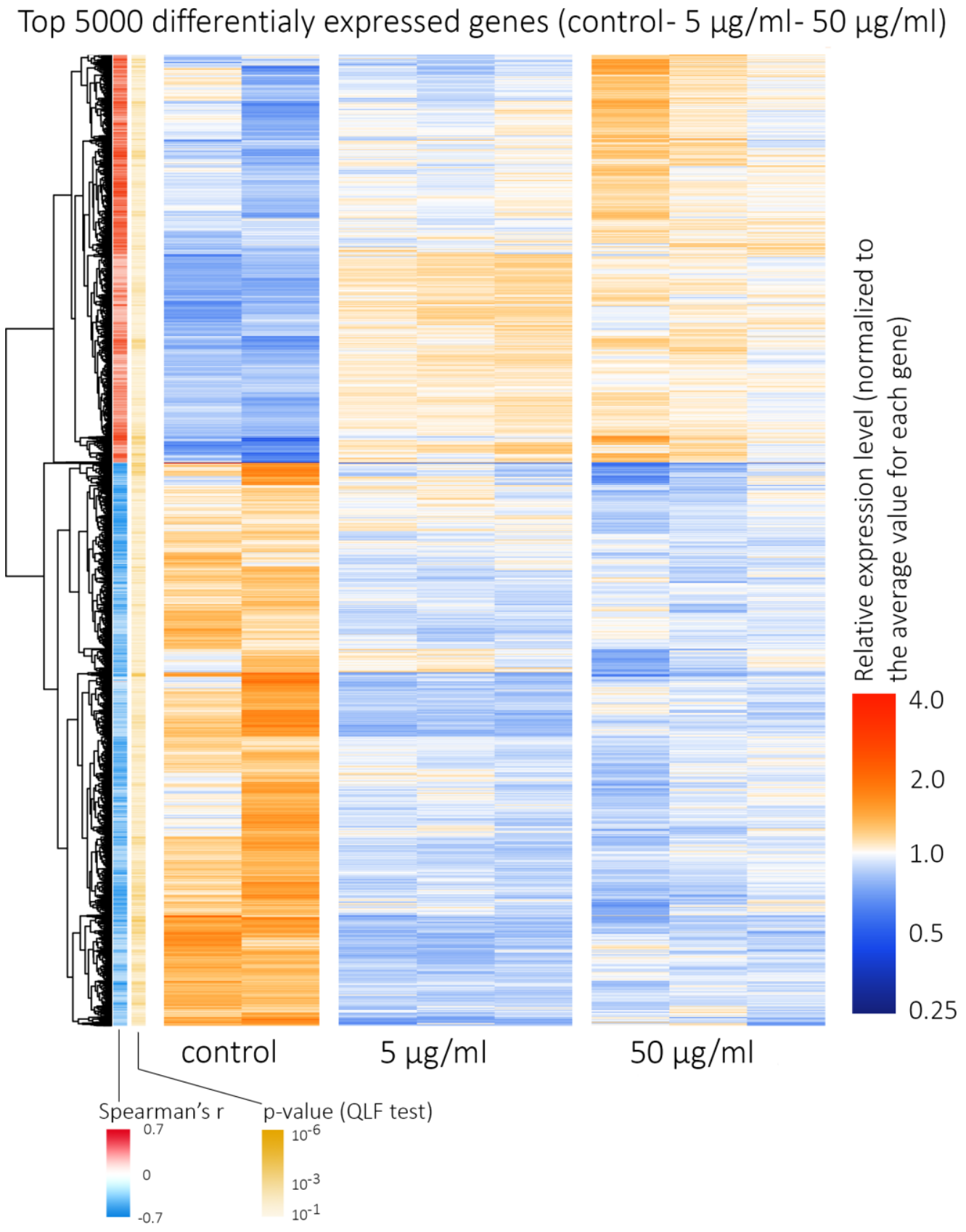

Supplementary Figure 3. Heatmap demonstrating expression level profiles of top 5000 genes (MRC5-SV40 cell line), expression of which gradually increases/decreases with the increase of Abisyl concentration $(0 \mu \mathrm{g} / \mathrm{ml}-5 \mu \mathrm{g} / \mathrm{ml}-\mathbf{5 0}$ $\mu \mathrm{g} / \mathrm{ml})$. 


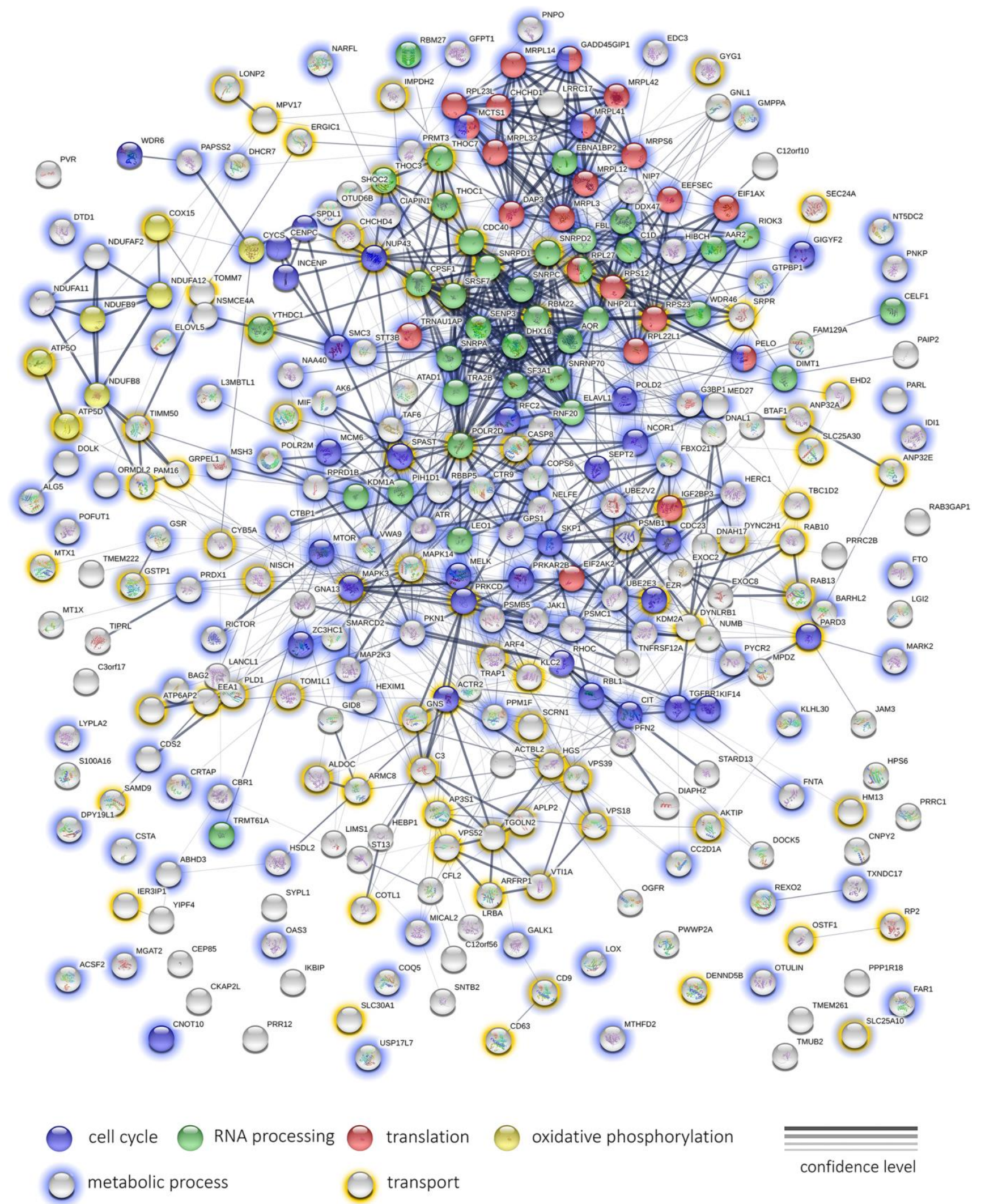

Supplementary Figure 4. The interaction network of top $\mathbf{3 0 0}$ proteins which content was decreased (or not detected) in MRC5-SV40 cells after Abisil treatment $(50 \mu \mathrm{g} / \mathrm{ml})$. The width of the connecting lines indicates the confidence level of protein interaction (best - mentions in curated databases, experimental data for human; worst - found interacting putative homologs in other organisms). 


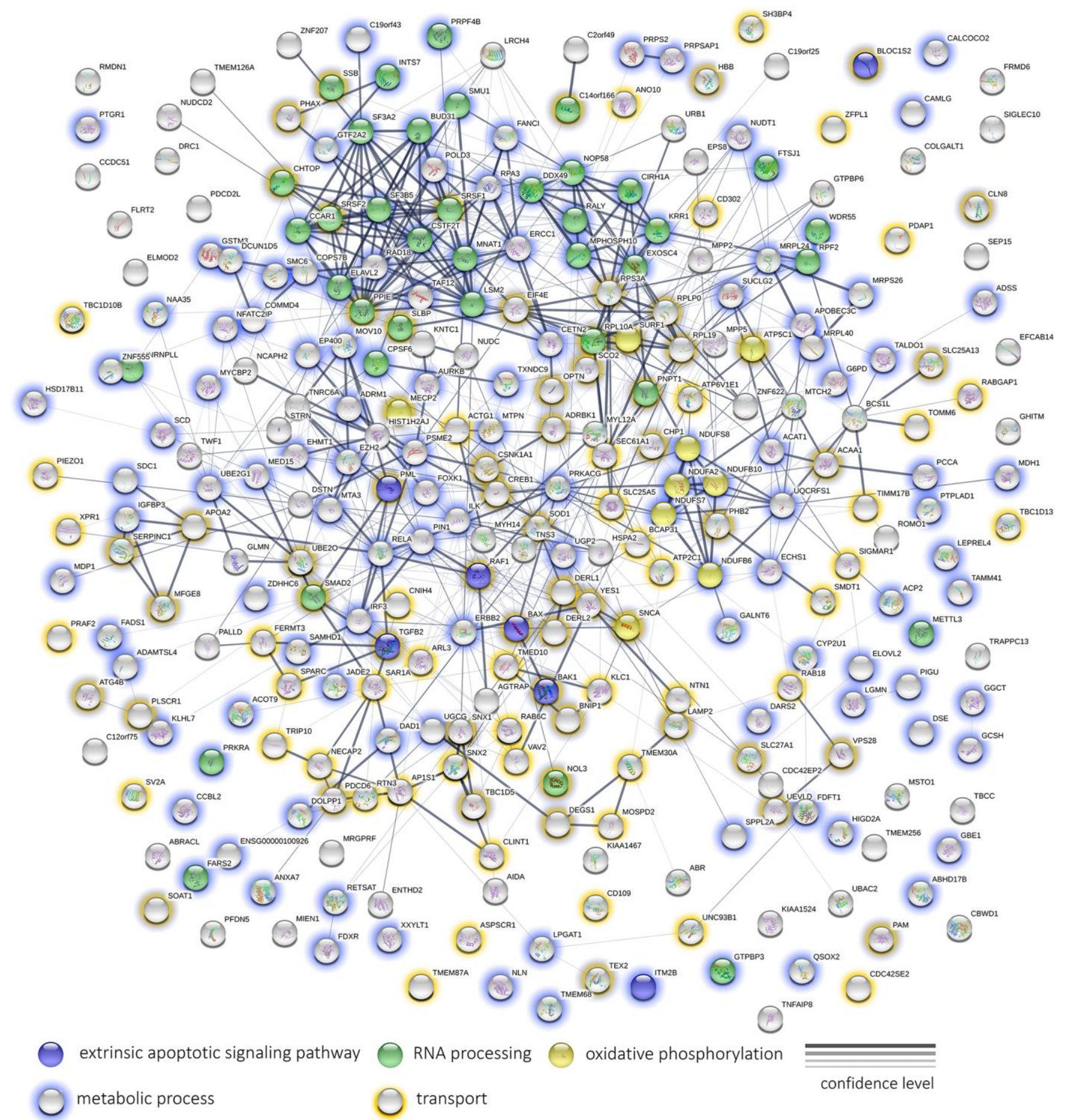

Supplementary Figure 5. The interaction network of top $\mathbf{3 0 0}$ proteins which content was increased in MRC5-SV40 cells after Abisil treatment (or detected only in treated cells). The width of the connecting lines indicates the confidence level of protein interaction (best - mentions in curated databases, experimental data for human; worst - found interacting putative homologs in other organisms). 


\section{Supplementary Tables}

Please browse Full Text version to see the data of Supplementary Tables 1-10.

Supplementary Table 1. The results of differential gene expression analysis between samples treated with lowconcentration Abisil (5 $\mathrm{\mu g} / \mathrm{ml})$ and control non-treated samples.

Supplementary Table 2. The results of differential gene expression analysis between samples treated with highconcentration Abisil $(50 \mathrm{\mu g} / \mathrm{ml})$ and control non-treated samples.

Supplementary Table 3. The results of differential gene expression analysis between samples treated with highconcentration Abisil $(50 \mu \mathrm{g} / \mathrm{ml})$ and samples treated with low-concentration $(5 \mu \mathrm{g} / \mathrm{ml})$.

Supplementary Table 4. The results of differential gene expression analysis: identification of genes, the expression of which gradually increases/decreases with the increase of drug concentration $(0 \mu \mathrm{g} / \mathrm{ml}-5 \mu \mathrm{g} / \mathrm{ml}$ $50 \mu \mathrm{g} / \mathrm{ml})$.

Supplementary Table 5. The results of Gene Ontology (biological processes) enrichment analysis for top 80, 250, 500 and 1000 up- or downregulated genes for the comparison of samples treated with low-concentration Abisil $(5 \mu \mathrm{g} / \mathrm{ml})$ to control non-treated samples.

Supplementary Table 6. The results of Gene Ontology (biological processes) enrichment analysis for top 80, 250, 500 and 1000 up- or downregulated genes for the comparison of samples treated with low-concentration Abisil $(50 \mathrm{\mu g} / \mathrm{ml})$ to control non-treated samples.

Supplementary Table 7. The results of Gene Ontology (biological processes) enrichment analysis for top 80, 250, 500 and 1000 up- or downregulated genes for the comparison of samples treated with high $(50 \mu \mathrm{g} / \mathrm{ml})$ and lowconcentration Abisil ( $5 \mu \mathrm{g} / \mathrm{ml})$.

Supplementary Table 8. The results of Gene Ontology (biological processes) enrichment analysis for top 80, 250, 500 and 1000 up- or downregulated genes, the expression of which gradually increases/decreases with the increase of drug concentration $(0 \mu \mathrm{g} / \mathrm{ml}-5 \mu \mathrm{g} / \mathrm{ml} \mathrm{-} 50 \mu \mathrm{g} / \mathrm{ml})$.

Supplementary Table 9. Differential expression of genes participating AMPK, mTOR pathways, and genes involved in mitophagy and autophagy.

Supplementary Table 10. The detailed results of proteome profiling of MRC5-SV40 cells treated with Abisil $(50 \mu \mathrm{g} / \mathrm{ml})$ compared to the non-treated cells. 